\title{
Experimental investigations on the bond behavior between concrete and FRP reinforcing bars
}

\author{
Arnaud Rolland ${ }^{a, *}$, Marc Quiertant ${ }^{\mathrm{b}}$, Aghiad Khadour ${ }^{\mathrm{c}}$, Sylvain Chataignerd, Karim \\ Benzarti $^{\mathrm{e}}$, Pierre Argoul ${ }^{\mathrm{b}}$
}

${ }^{\text {a } C e r e m a, ~ F-59482 ~ H a u b o u r d i n, ~ F r a n c e ~}$

${ }^{\mathrm{b}}$ Université Paris-Est, MAST, EMGCU, IFSTTAR, F-77447 Marne-la-Vallée, France

${ }^{\mathrm{c}}$ Université Paris-Est, COSYS, LISIS, IFSTTAR, F-77447 Marne-la-Vallée, France

${ }^{\mathrm{d}}$ IFSTTAR, MAST, SMC, Route de Bouaye, F-44344 Bouguenais, France

${ }^{\text {e }}$ Université Paris-Est, Laboratoire Navier (UMR 8205), CNRS, Ecole des Ponts Paris Tech, IFSTTAR, F-77455 Marne-la-Vallée, France

* Corresponding author: arnaud.rolland@ cerema.fr (A. Rolland)

\section{Highlights}

- Bond properties of selected commercially available FRP rebars embedded in concrete were investigated from pull-out tests.

- Distributed Optical Fiber Sensors (DOFS) enabled continuous strain measurement along the rebar/concrete interface and provided access to the local bond behavior.

- An emphasis was made on the effect of various parameters (nature of the fibers, diameter and surface characteristics of the rebar) on the bond-slip behavior and on the effective development length of rebars. Characteristics of the sand particles from the surface coating were found to play a major role on the load transfer mechanism. 
- Intrusive effect of DOFS instrumentation was found to depend on the type of FRP rebar. In few cases, DOFS affected significantly the results of pull-out tests.

\title{
Keywords
}

Composites, FRP bars, Bond, Pull-out tests, Distributed optical fiber sensors, Development length

\begin{abstract}
This study focuses on the experimental characterization of the bond behavior between concrete and Fiber Reinforced Polymer (FRP) reinforcing bars (rebars). Pull-out tests were performed on glass, carbon, and aramid FRP rebars, as well as on deformed steel rebars. The influence of various parameters on the bond behavior was studied, such as the type of fibers, the diameter of the FRP bars and their surface geometry. Scanning-Electron-Microscope (SEM) observations were performed to precisely study the sand coating characteristics of these rebars. A main originality of the proposed approach relied on the instrumentation of pull-out samples using Distributed Optical Fiber Sensing (DOFS) instrumentation. Such a distributed measurement system provided access to the longitudinal strain distribution along the rebar near the rebar-concrete interface, and then made it possible to determine the effective development length of the various types of rebars considered in this study. As the introduction of DOFS instrumentation may be intrusive, its influence on the interface behavior was also discussed.
\end{abstract}

\section{Introduction}

Corrosion of steel reinforcing bars (rebars) is the main cause of degradation of Reinforced Concrete (RC) structures, and has large incidence on maintenance / repair expenses. To 
prevent such degradations of new infrastructures, the use of corrosion-free reinforcements, such as Fiber-Reinforced Polymer (FRP) rebars is gaining interest. The main products available on the market are made from Glass (GFRP), Carbon (CFRP), Aramid (AFRP) or Basalt (BFRP) fiber reinforced polymers. In these materials, polymer matrices are usually based on thermosetting resins, such as vinylester or epoxy systems. Compared to steel reinforcement, FRP rebars have the advantage of being lighter, stronger in tension, corrosion resistant, and electromagnetically neutral (with the exception of CFRP bars).

A key point controlling the performances of FRP reinforced structures is the bond behavior between the rebar and concrete. Indeed, interfacial properties are critical with respect to the load transfer mechanism between concrete and its reinforcement. In current design practices, bond properties govern serviceability, ductility and ultimate capacity of RC structures. Eurocode 2 [1] states that "the ultimate bond strength shall be sufficient to prevent bond failure". However, designing FRP RC structures is not trivial as the bond behavior of FRP rebars with concrete is affected by many factors, such as concrete strength, rebar stiffness (depending upon constitutive materials, especially the type and volume ratio of fibers), surface geometry and coating, adherence between the surface coating and the core of the FRP bar, the type of polymer matrix, and the fiber/matrix interface properties as well [2-5].

At the structural scale, FRP/concrete bond properties play a very important role with respect to in-service deformations (deflections), but also to cracking of the concrete cover.

The most common methods used to assess the bond behavior of FRP rebars with concrete are the direct pull-out test and the bond beam test. Described in ACI 440.3R-04 [6], Rilem recommendations [7] and EN 10080 [8], the direct pull-out test is the simplest test to conduct, and has been applied in many previous studies dedicated to the bond performance of FRP bars [2-5, 9-11] embedded in concrete. 
During bond tests, measured quantities are typically the maximum applied load and the overall slippage of the FRP reinforcement. However, these measures cannot provide local information regarding the interfacial behavior, and are thus unable to assess the effective development length.

Besides, DOFS technologies are gaining interest in civil engineering applications [12]. They allow continuous strain measurement along the optical fiber attached to the host structures, with a sub-centimeter spatial resolution, while being only little intrusive. Such an instrumentation method has already been implemented for pull-out tests in previous studies devoted to the bond behavior between reinforcing steel rebars and Ultra-High Performance Fiber-Reinforced Concrete [13-15], but to the authors' knowledge, it has never been explored in the case of FRP reinforced concrete.

The present study investigates the local bond behavior between FRP rebars and concrete. The interfacial load transfer mechanism was characterized by pull-out tests carried out on RC specimens equipped with a DOFS instrumentation. Such an approach was applied to a selection of various FRP bars available on the market.

A special attention was paid to the influence of various features of the FRP rebars, such as the nature of the fibers, the internal microstructure (presence of flaws, fiber arrangement), the surface characteristics (geometry and sand coating), or the rebar diameter, on the interfacial mechanical behavior. In addition, an analysis of the strain profiles recorded by the DOFS system made it possible to evaluate the effective development lengths for the various FRP bars under consideration. Moreover a comparison of pull-out tests performed on RC specimens equipped with DOF sensors and non-instrumented specimens, gave information regarding the intrusiveness of the proposed DOFS methodology. 


\section{Experimental program}

\subsection{Materials}

Various rebars available on the international market were selected for this study, based on glass, aramid or carbon fibers. Corresponding series are named GLASS, CARBO and ARA, respectively. These FRPs are manufactured by pultrusion process, with the exception of ARA rebars, which are produced from Kevlar braided ropes. Table 1 gathers information regarding the manufacturers, commercial brands, nature and volume contents of fiber and polymer matrix constituents, and type of manufacturing process for all series of FRP rebars.

For each series, the FRP materials were supplied with different surface finishes, either sand coated or plain (smooth, without additional surface coating). Corresponding sub-series are labelled xxx-S and xxx-NS respectively. Note that in practice, only sand-coated rebars of the GLASS type and CARBO type are commercialized on the market for construction applications. However, GLASS-NS and CARBO-NS have been studied in order to evaluate the effect of the sand-coating on the bond behavior of these rebars.

Various rebar diameters were considered, which are also specified in the samples designation. For the sake of comparison, conventional deformed steel rebars (named STEEL-D-12) were also considered in this work.

The main characteristics of all rebars under study are detailed in Table 2. Typical aspects of these rebars are shown in Fig 1. It is to note that ARA rebars present a specific surface geometry made of concavo-convex shapes due to the braiding process, which is supposed to improve their bond capacity with concrete. With regard to CARBO series, one can notice the presence of a white multifilament yarn helically wrapped around the bar which creates an additional surface relief. This feature is observed both on uncoated (CARBO-NS) and sand coated (CARBO-S) rebars. 
Table 1. Commercial information on the selected FRP rebars

\begin{tabular}{|c|c|c|c|c|c|}
\hline Series & $\begin{array}{l}\text { Commercial } \\
\text { brand }\end{array}$ & Manufacturer & $\begin{array}{l}\text { Type of fibers / } \\
\text { matrix }\end{array}$ & $\begin{array}{l}\text { Fiber content } \\
\text { (vol.\%) }\end{array}$ & $\begin{array}{l}\text { Manufacturing } \\
\text { process }\end{array}$ \\
\hline GLASS & V.Rod ® & $\begin{array}{l}\text { Pultrall @, } \\
\text { Canada }\end{array}$ & $\begin{array}{l}\text { E-glass / } \\
\text { vinylester }\end{array}$ & 65 & Pultrusion \\
\hline CARBO & Carbopree ${ }^{\circledR}$ & Sireg ${ }^{\circledR}$, Italia & $\begin{array}{l}\text { Carbon / } \\
\text { vinylester }\end{array}$ & 65 & Pultrusion \\
\hline ARA & Fibra ${ }^{\circledR}$ & Fibex ${ }^{\circledR}$, Japan & $\begin{array}{l}\text { Kevlar } 49 \text { ® } \\
\text { Aramid / epoxy }\end{array}$ & 60 & Braided rope \\
\hline
\end{tabular}

Table 2. Designations and main characteristics of the rebars under study

\begin{tabular}{|c|c|c|c|c|}
\hline Series & Subseries & $\begin{array}{l}\text { Rebar } \\
\text { designation }\end{array}$ & Surface finish & $\begin{array}{l}\text { Nominal } \\
\text { diameter } \\
(\mathrm{mm})\end{array}$ \\
\hline \multirow{4}{*}{ GLASS } & \multirow{3}{*}{ GLASS-S } & GLASS-S-9.5 & Sanded & 9.5 \\
\hline & & GLASS-S-12.7 & Sanded & 12.7 \\
\hline & & GLASS-S-15.9 & Sanded & 15.9 \\
\hline & GLASS-NS & GLASS-NS-12.7 & Non-sanded & 12.7 \\
\hline \multirow{3}{*}{ CARBO } & \multirow{2}{*}{ CARBO-S } & CARBO-S-7.5 & $\begin{array}{l}\text { Sanded + } \\
\text { helically } \\
\text { wrapped yarn }\end{array}$ & 7.5 \\
\hline & & CARBO-S-10 & $\begin{array}{l}\text { Sanded + } \\
\text { helically } \\
\text { wrapped yarn }\end{array}$ & 10 \\
\hline & CARBO-NS & CARBO-NS-10 & $\begin{array}{l}\text { Non-sanded } \\
+ \text { helically } \\
\text { wrapped yarn }\end{array}$ & 10 \\
\hline \multirow{3}{*}{$A R A$} & \multirow{3}{*}{ ARA-S } & ARA-S-5 & $\begin{array}{l}\text { Braided and } \\
\text { Sanded }\end{array}$ & 5 \\
\hline & & ARA-S-9 & $\begin{array}{l}\text { Braided and } \\
\text { Sanded }\end{array}$ & 9 \\
\hline & & ARA-S-15 & $\begin{array}{l}\text { Braided and } \\
\text { Sanded }\end{array}$ & 15 \\
\hline \multicolumn{2}{|c|}{ STEEL-D-12 } & & Deformed & 12 \\
\hline
\end{tabular}




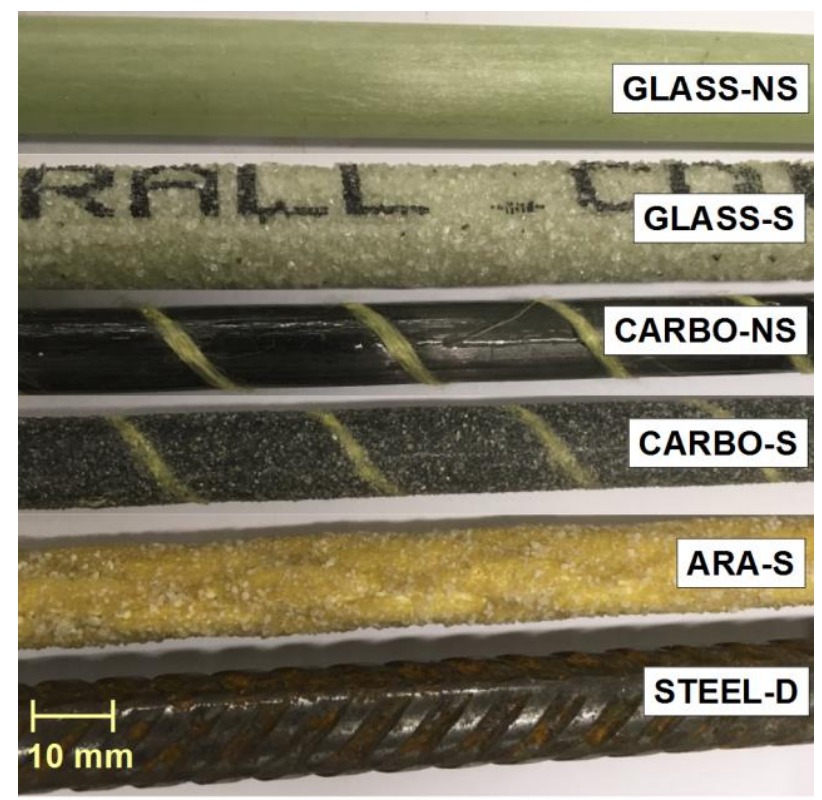

Fig 1. Visual aspects of the selected FRP rebars and the reference steel rebar

Elastic moduli and tensile strengths of the various series of rebars were evaluated by tensile tests, according to ASTM D7205/D7205M-06 standard [16]. Further details regarding the experimental procedure adopted for tensile tests (especially the anchorage system used for preventing bar breakage in the grips of the testing machine) can be found in $[\mathbf{1 7}, \mathbf{1 8}]$. These tests were conducted for a single diameter value of each series, although many studies have reported a size dependence of the longitudinal strength for FRP rebars [19, 20]. The main objective here, is to check that the supplied FRP materials fulfill the properties claimed by the manufacturers. Mean values of the tensile properties based on five repeated tests, together with the corresponding guaranteed properties, are listed in Table 3 for the various series of rebars.

Globally, test results are found in agreement with values of tensile strength and modulus announced by the various FRP suppliers, with the exception of samples from the ARA series, for which significantly higher values can be noted compared to those reported by the manufacturer. 
Table 3. Results of tensile tests for the 3 series of FRP rebars and the reference steel bar

\begin{tabular}{llllll}
\hline Type of rebar & $\begin{array}{l}\text { Ultimate } \\
\text { load (kN) }\end{array}$ & $\begin{array}{l}\text { Tensile } \\
\text { strength } \\
(\mathbf{M P a})\end{array}$ & $\begin{array}{l}\text { Manufacturer's } \\
\text { value } \\
(\mathbf{M P a})\end{array}$ & $\begin{array}{l}\text { Elastic } \\
\text { modulus } \\
(\mathbf{G P a})\end{array}$ & $\begin{array}{l}\text { Manufacturer's } \\
\text { value } \\
(\mathbf{M P a})\end{array}$ \\
\hline GLASS-S-9.5 & $81 \pm 3$ & $1140 \pm 50$ & 1100 & $53 \pm 2$ & 52.5 \\
\hline $\boldsymbol{C A R B O}-\boldsymbol{S}-7.5$ & $96 \pm 9$ & $2200 \pm 200$ & 2300 & $139 \pm 4$ & 130 \\
\hline $\boldsymbol{A R A}-\boldsymbol{S}-5$ & $37 \pm 1$ & $1870 \pm 30$ & 1100 & $80 \pm 3$ & 68.6 \\
\hline STEEL-D-12 & $68 \pm 1$ & $600 \pm 9$ & 500 & $198 \pm 1$ & 200 \\
\hline
\end{tabular}

\subsection{Test setup for characterizing concrete/rebar interface behavior}

The bond behavior between the rebars and concrete has been characterized by direct pull-out tests, according to ACI 440.3R-04 standard [6]. The test setup and loading conditions are depicted in Fig 2. RC specimens consist of a 1.20 meter-long straight rebar partially embedded, with centric placement, in a normal strength concrete cylinder $(16 \mathrm{~cm}$-diameter and $20 \mathrm{~cm}$-height). Concrete was cast, while the rebar was set in the vertical position. A plastic tube, called bond breaker, is placed between the rebar and concrete near the loaded side of the concrete block, in order to prevent edge effects induced by the reaction support. For each RC specimen, the length of the bond breaker is chosen so that the embedment length of the bar in concrete is equal to six bar diameter (Fig 2.b). Such a condition is supposed to favor a preferential failure by slippage of the rebar [10].

All the pull-out specimens were made from the same batch of a normal strength concrete, formulated with aggregates with a maximum size of $22 \mathrm{~mm}$. Compressive strength of the concrete was evaluated on three cylindrical specimens $(16 \mathrm{~cm}$ diameter and $32 \mathrm{~cm}$ height $)$ after 37 days of cure out of water (the testing machine was not available at 28 days of cure). The tests resulted on a mean compressive strength of $28.1 \pm 0.4 \mathrm{MPa}$. More details of the compressive tests are available in [17]. 
Pull-out tests were conducted five month after the casting of the specimens, using a $350 \mathrm{kN}$ universal testing machine. The RC specimens were put on the drilled horizontal crosshead beam of the machine, with the rebar passing through the beam hole (Fig 2.a). The test is controlled by the grip displacement at a constant speed of $1.2 \mathrm{~mm} / \mathrm{min}$. During the test, the free end slip of the rebar is monitored with a non-contact laser displacement sensor located at an initial distance of $40 \mathrm{~mm}$ from the end of the bar. This sensor allows measurement on a range of $20 \mathrm{~mm}$ with a precision less than $10 \mu \mathrm{m}$.
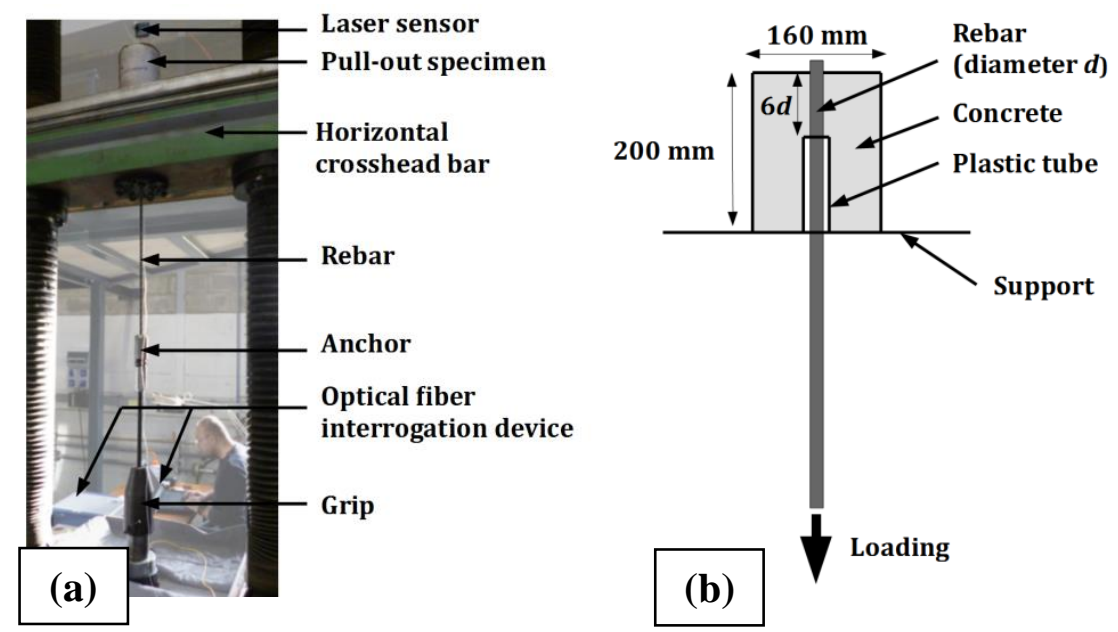

Fig 2. Pull-out tests: (a) Experimental setup and (b) loading conditions

\subsection{Distributed Optical Fiber Sensing}

For each series of pull-out specimens, several rebars were equipped with a DOFS sealed into a groove drilled along the bar length, prior to embedment in concrete. The optical fiber sensor was then connected to a commercially available interrogation unit consisting of an Optical Rayleigh Frequency-Domain Reflectometer (OFDR). This optoelectronic device correlates two OFDR traces (recorded for example before and after loading of the sample) and then converts the spectral shift into strain. Such a measuring device allows distributed 
measurement of the longitudinal strain of the rebar with a gauge length less than $5 \mathrm{~mm}$, while remaining less intrusive than electrical strain gauges [12, 21, 22].

Prior to concrete casting, the rebars were grooved over a length of $300 \mathrm{~mm}$, with a width of 1 $\mathrm{mm}$ and a depth of $2 \mathrm{~mm}$ (Fig 3). The fiber was then sealed into the U-groove using a twopart fast curing methyl methacrylate-based adhesive.
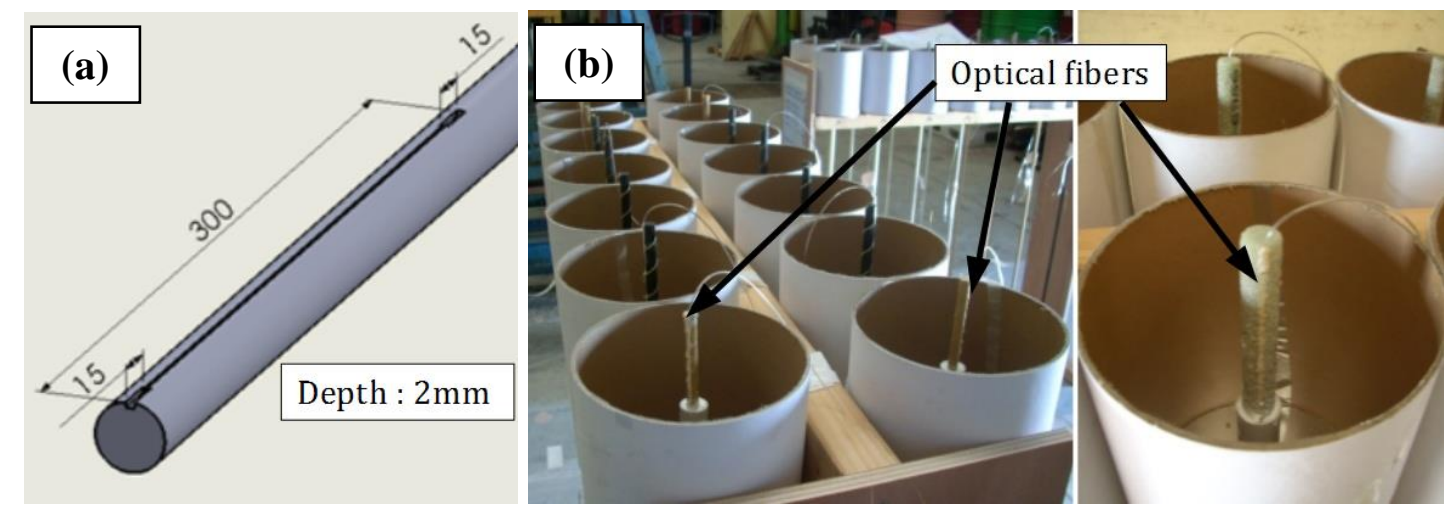

Fig 3. DOFS instrumentation: (a) Geometry of the U-groove at the surface of the rebar and (b) Pull-out specimens instrumented with DOFS prior to concrete casting

During the pull-out tests, DOFS measurements were recorded at different loading stages. The displacement of the grip was kept constant during these stages to allow the acquisition of the strain profile.

\section{Results and discussions}

\subsection{Preliminary microstructural observations by scanning electron microscopy}

As the surface characteristics of FRP rebars are known to influence the bond behavior with concrete, micrographic observations of the sand coated surfaces were performed for the various series of rebars. Such observations were made on polished cross sections of the rebars, using a Hitachi S570 Scanning Electron Microscope (SEM) operating in secondary electron mode, with a picture resolution in the order of one $\mu \mathrm{m}$. The purpose of these 
observations was to qualitatively evaluate the microstructure of the different rebars (size and shape of the sand particles of the surface coating, homogeneity of the fiber arrangement within the FRP bar, cohesion of the fiber/matrix interface), and to detect the possible presence of manufacturing defects (debonding, voids) which may affect the mechanical performances of these rebars.

Fig 4 shows typical SEM micrographs at low magnification for the various series of sand coated rebars. These pictures make it possible to identify the internal composite structure and to determine the size of the sand particles of the surface coating. This particle size appears to be higher for rebars of GLASS and ARA series (diameter in the range 0.5 to $1.0 \mathrm{~mm}$ ) than for CARBO series (diameter in the range $0.1-0.5 \mathrm{~mm}$ ). In addition, sand particles of the ARA series are found to exhibit a much smoother and less angular shape compared to that of the other series.

Higher-magnification SEM pictures provided in Fig 5 facilitate the visualization of the local fiber arrangement and the possible presence of defects. Globally, the fiber distribution is found rather compact and homogeneous for GLASS and ARA series, and no significant flaws are detected for these FRP materials. Differently, numerous voids can be observed on the cross sections of CARBO rebars, both at low and high magnifications (Fig 4 and Fig 5), even if these voids are not visible to the naked eye (size in the order of $0.1 \mathrm{~mm}$ ). 


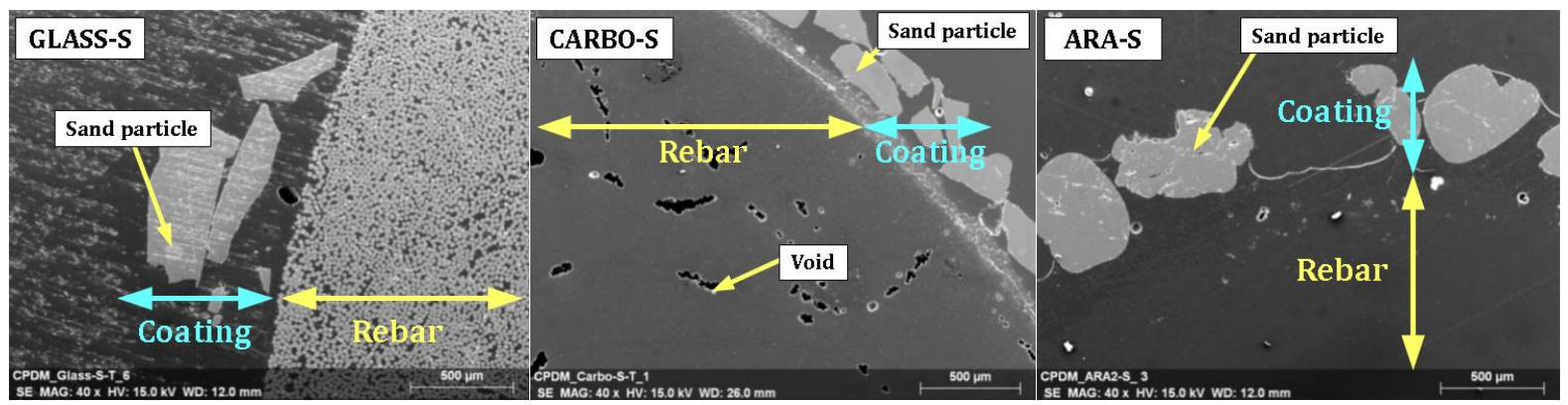

Fig 4. SEM micrographs of polished cross sections at low magnification, for the various series of sand coated FRP rebars

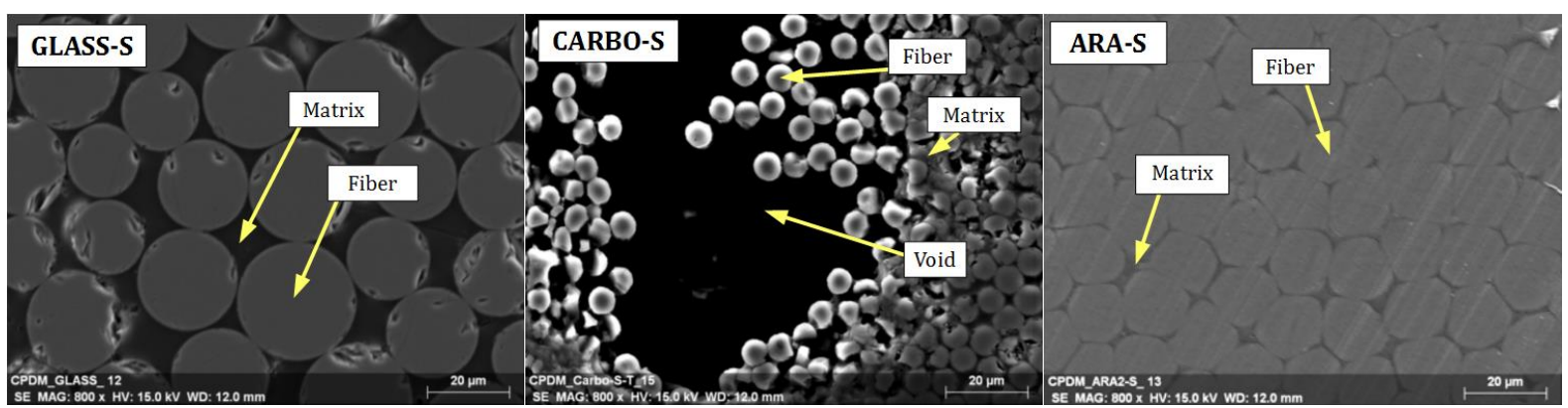

Fig 5. SEM micrographs of polished cross sections at high magnification, for the various series of sand coated FRP rebars

\subsection{Characterization of the bond-slip behavior by Pull-out test}

Pull-out tests were performed on RC specimens made with the various rebars listed in Table 2, with the exception of CARBO-S 7.5 et ARA-S-5 (which were only tested in tension). For each type of reinforcement (same material, diameter and surface treatment), four RC specimens were tested, among which two were instrumented by DOFS. The aim of this experimental program was to study the effects of i) the nature of the fibers, ii) the diameter of the bars and iii) the surface characteristics (with or without sand coating, characteristics of the sand coating, braided structure in the case of ARA series) on the bond behavior between FRP rebars and concrete. Besides, by comparing the mechanical responses of RC specimens with and without DOFS, the intrusiveness of such instrumentation could also be assessed. 


\subsubsection{Failure modes}

Typical failure modes of the various pull-out specimens are shown in Fig 6. For all RC specimens, the failure occurred by slippage of the rebar out of the concrete cylinder, which was the expected pull-out failure mode.

Observation of extracted rebars reveals that a thin layer of concrete remains attached to all sand coated FRP rebars (GLASS-S, CARBO-S and ARA-S series) and to the ribs of STEELD rebars as well. Differently, such a layer is not observed for non-sanded FRP rebars (GLASS-NS and CARBO-NS series). In the case of rebars of the GLASS-S series, a mixed failure mode was observed, with a partial peeling off of the sand coated layer along the extracted part of the bar, as depicted on the first picture of Fig $\mathbf{6}$.
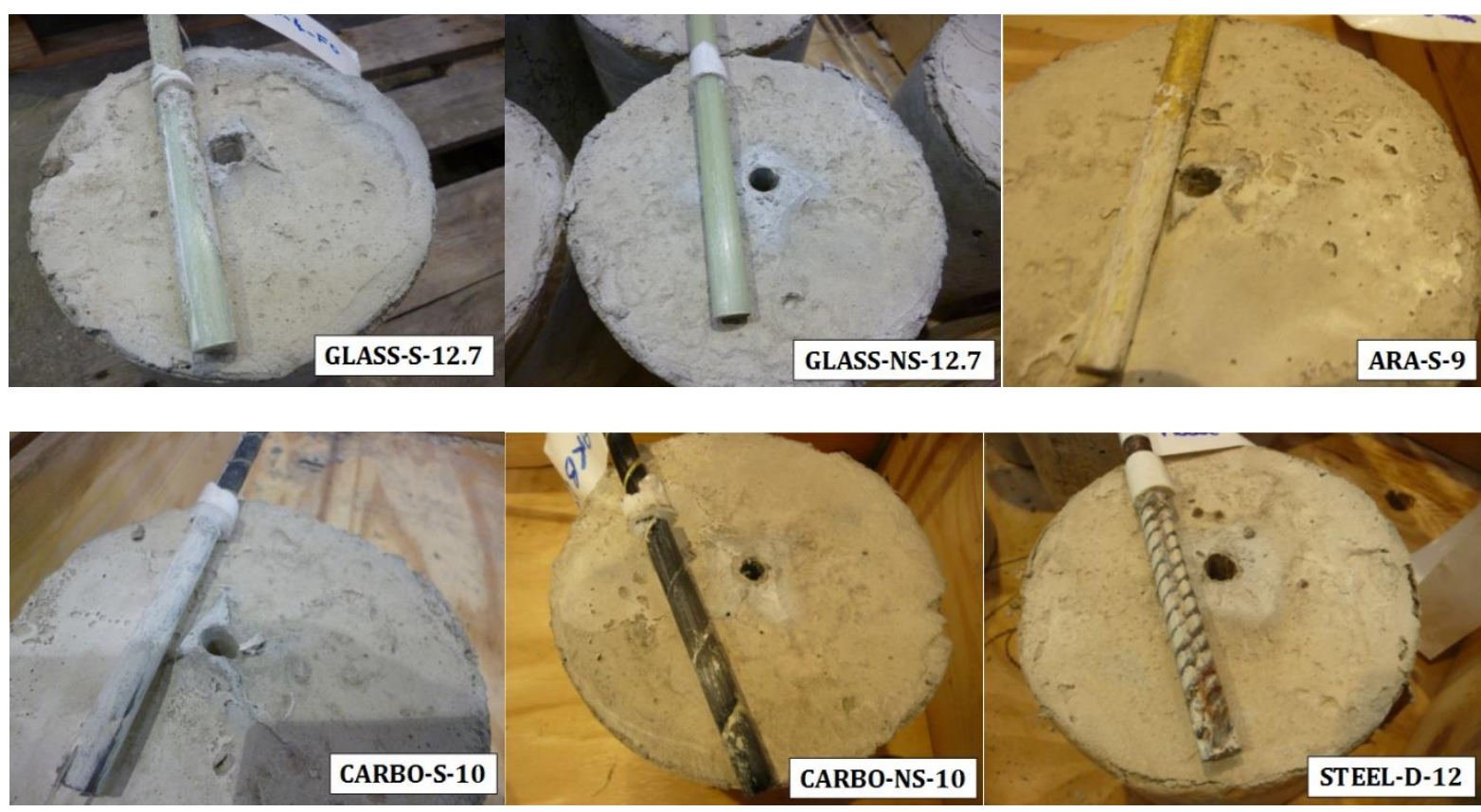

Fig 6. Typical failure modes observed for the various pull-out specimens 


\subsubsection{Bond-slip behavior}

The evolution curves of the average shear stress versus the free end slip of the rebar, obtained from the pull-out experiments on the various series of RC specimens are shown in Fig 7 to Fig 11. In each figure, the four RC specimens are labeled name-1 and name-2 for the noninstrumented specimens, and name-3-OF and name-4-OF for the specimens instrumented with DOFS.

On the curves corresponding to the instrumented specimens, several load drops can be observed, corresponding to a decreasing of the force exerted by the testing machine during the acquisition of the strain profiles (the displacement of the grip was kept constant during the acquisition stages).

The average bond stress at any stage of the loading scheme, noted $\tau_{m}$, is calculated as the ratio of the tensile force $F$ applied at the loaded end, to the bonded area of the rebar with surrounding concrete. It is expressed as follows:

$$
\tau_{m}=\frac{F}{\pi d L_{E}}
$$

where $d$ is the diameter of the rebar and $L_{E}$ is the embedded length $\left(L_{E}=6 d\right)$. The bond strength is defined as the maximum value of the average shear stress recorded during the test. Note that the free end slip of the rebars GLASS-NS-12.7-2 and ARA-S-9mm-4-OF was not recorded due to a dysfunction of the displacement sensor during test. Thus, the corresponding bond-slip curves are not displayed in Fig 8.b and Fig 11.a. 


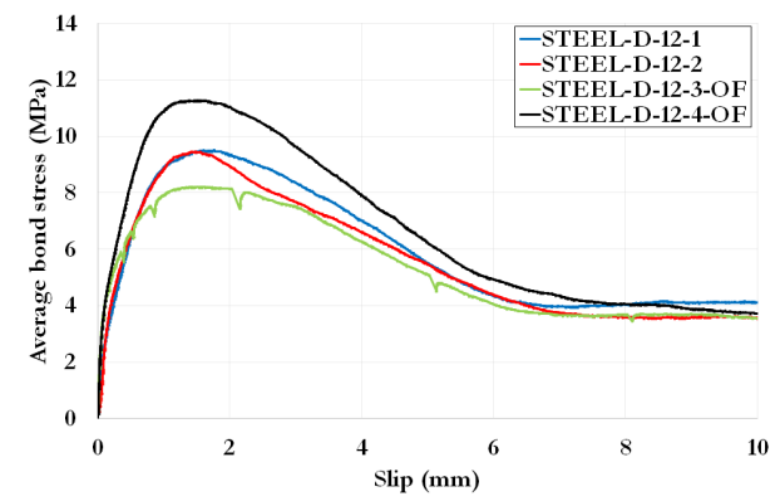

Fig 7. Bond-slip curves for RC specimens with STEEL-D-12 rebars
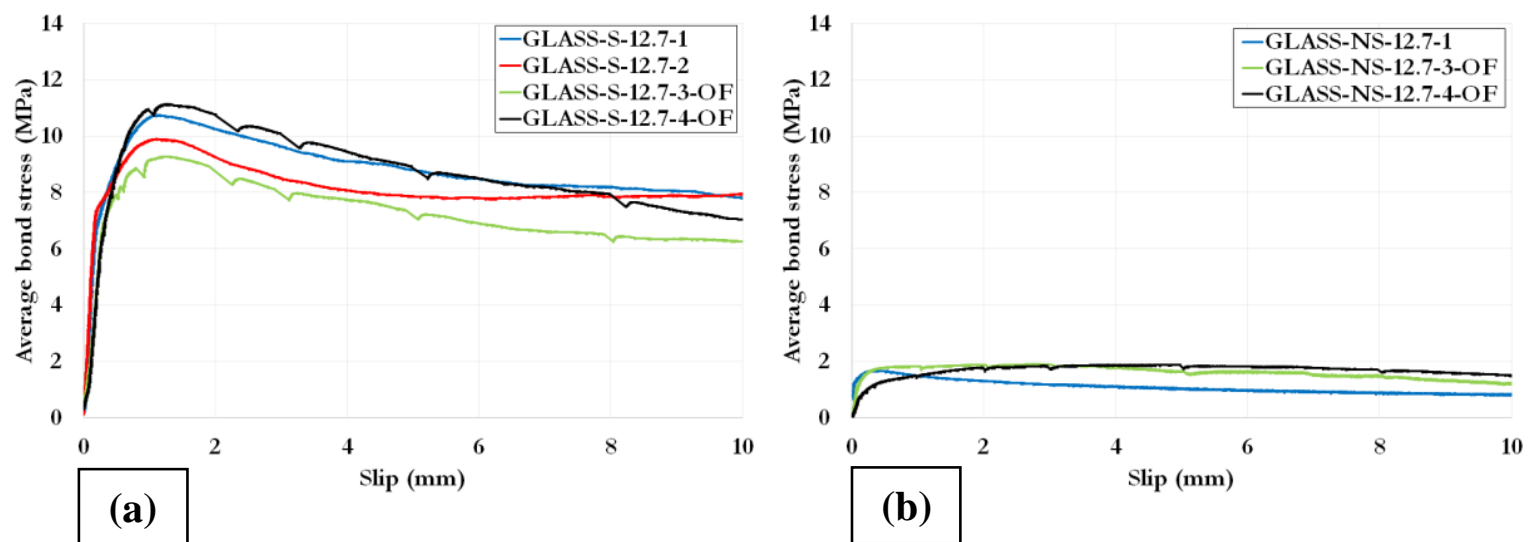

Fig 8. Bond-slip curves for RC specimens with (a) GLASS-S-12.7 and (b) GLASS-NS-12.7 rebars
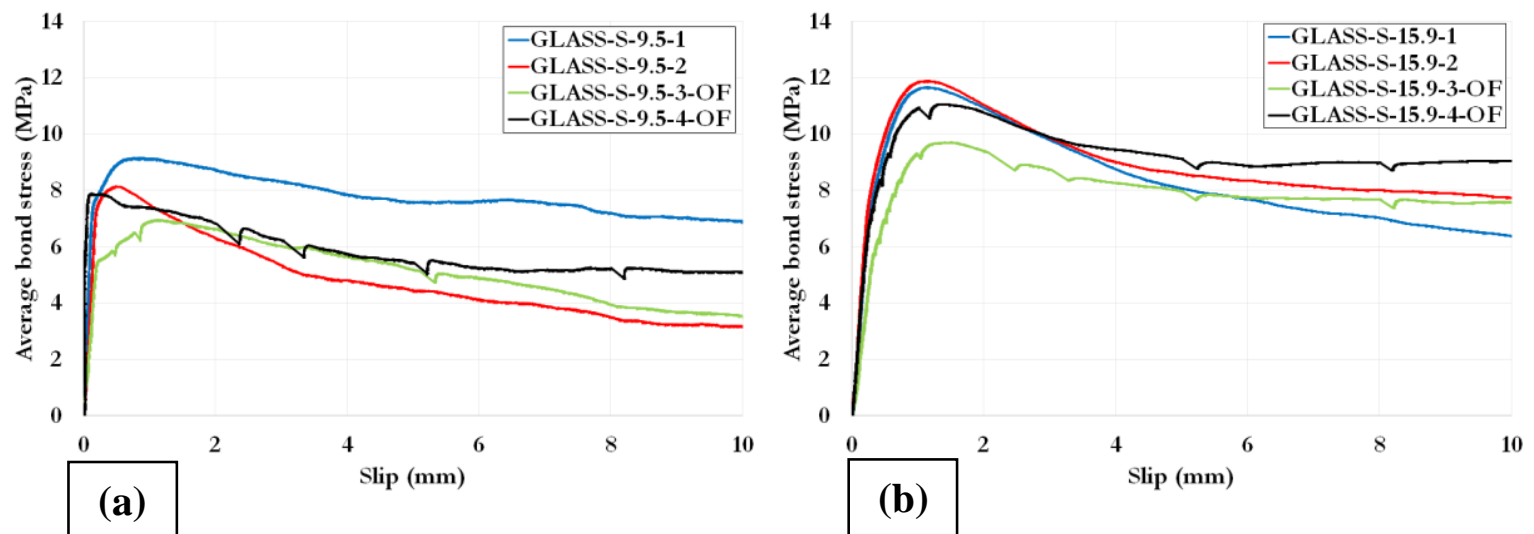

Fig 9. Bond-slip curves for RC specimens with (a) GLASS-S-9.5 and (b) GLASS-S-15.9 rebars 

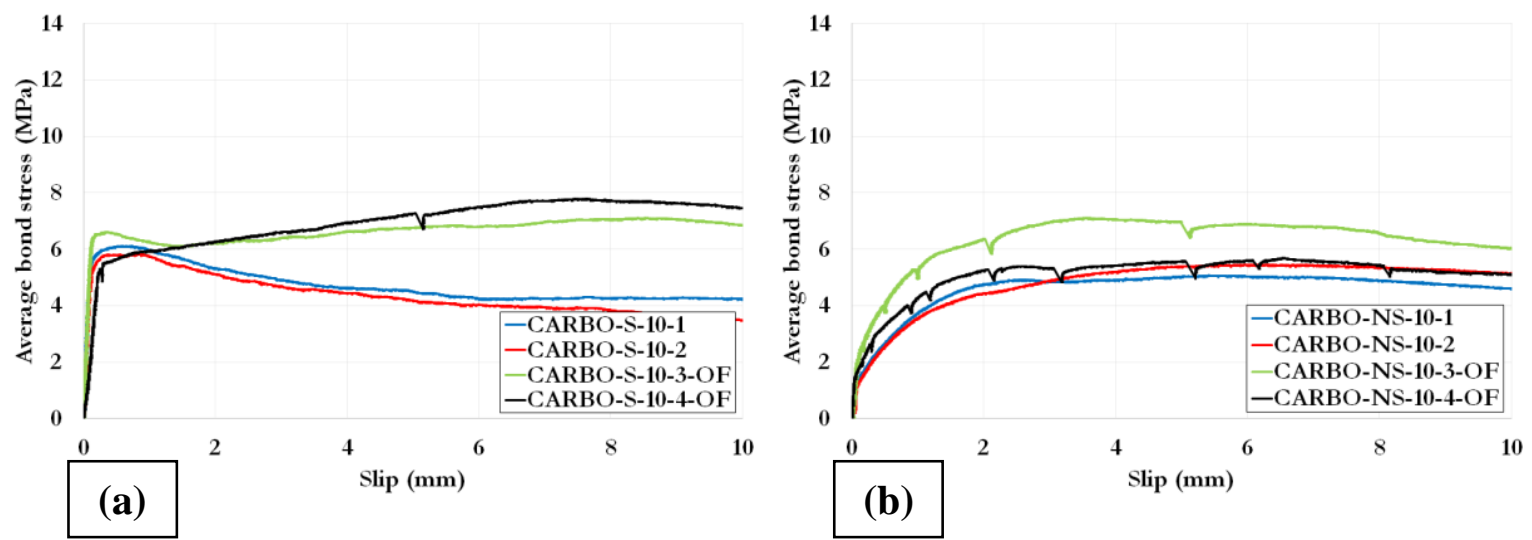

Fig 10. Bond-slip curves for RC specimens with (a) CARBO-S-10 and (b) CARBO-NS-10 rebars
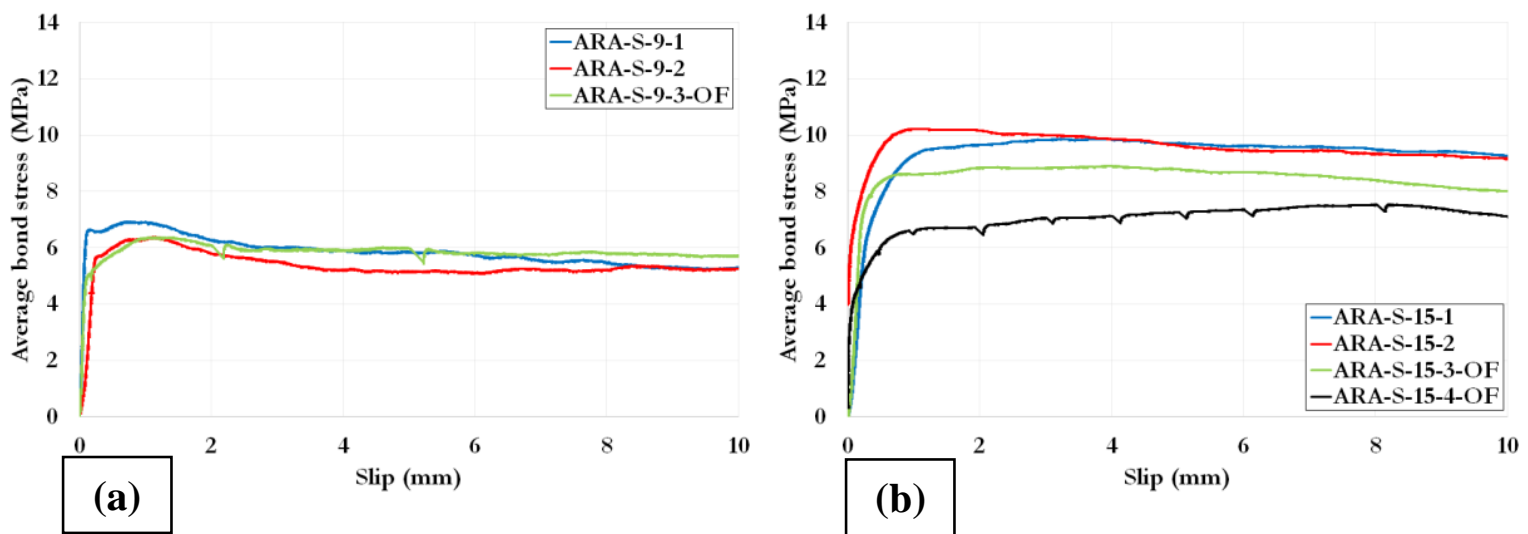

Fig 11. Bond-slip slip curves for RC specimens with (a) ARA-S-9 and (b) ARA-S-15 rebars

Average values of the ultimate capacity and bond strength are listed in Table 4, for each type of specimens. Mean values provided in this table are also summarized in the bar graph depicted in Fig 12, where error bars relates to standard deviations. In addition, Fig 13 provides a comparison of typical bond-slip curves representative of the different rebars.

Globally, specimens with rebars of the GLASS-S series (sand coated) exhibit the highest bond strengths in the present test configuration. Furthermore, it is interesting to note that specimens with GLASS-S-12.7 rebars present slightly higher bond strength compared to specimens with STEEL-D-12 rebars, for a quasi equivalent diameter of the embedded bar $(12.7 \mathrm{~mm}$ and 12 $\mathrm{mm})$. Most of the time, the literature reports that bond strength of GFRP rebars do not exceed that of steel reinforcement $[\mathbf{2}, \mathbf{5}]$ in the case of a conventional pull-out failure mode. However, 
results obtained in the present study with the GLASS-S series show opposite trend and are thus are considered very promising for future use of FRP bars as internal reinforcement for concrete.

Besides, the sand coating is found to be very effective in the case of GLASS rebars. Indeed, the bond strength obtained for specimens with GLASS-S-12.7 rebars is six times higher than that of specimens with uncoated GLASS-NS-12.7 rebars. As previously underlined (Fig 1), the latter uncoated rebars present a very smooth surface, which obviously reduces dramatically the bond properties with concrete.

Regarding pull-out tests performed on specimens of the CARBO series, and particularly on those with CARBO-NS-10 and CARBO-S-10 rebars, it appears that sand coating has, this time, a more limited effect on the bond strength value. A possible explanation is that the size of sand particles (hence the surface roughness of the coated rebar) is significantly smaller in the case of CARBO-S rebars compared to GLASS-S rebars, as previously shown by SEM observations (Fig 4). Thus, the contribution of the sand particles to interfacial adherence by a mechanical anchoring phenomenon or by friction appears to be lower for CARBO-S than for GLASS-S rebars. In addition, both sand coated and uncoated CARBO rebars present a periodic surface relief due to the helically wrapped white yarn, as previously shown in Fig $\mathbf{1}$. Such a relief may contribute to interfacial adherence independently of the sand coating, hence providing another explanation for the similar bond strength values obtained for specimens with CARBO-NS-10 and CARBO-S-10 rebars. Nevertheless, a closer comparison of the bond-slip curves of these specimens reveals that sand coating still plays an important role in the initial interface stiffness. Such a trend was already reported in the literature $[\mathbf{3 , 5}, \mathbf{1 0}]$. With regard to specimens with sand coated aramid FRP rebars, it is found that ARA-S-9 samples present a lower bond strength compared to specimens with GLASS-S-9.5 and CARBO-S-10 rebars, despite their braided geometry (note that the comparison is made at 
nearly equivalent bar diameter). One possible explanation lies in the fact that sand particles of the surface coating are smoother and less angular for rebars of the ARA series, as shown in Fig. 4.

Optical fiber instrumentation was expected to be a non-intrusive tool compared to other measurement systems, like strain gauges, due to the low diameter of the fiber, the modest size of the groove and absence of connecting wire except the fiber itself. However, if this nonintrusiveness was actually observed in most of the experiments (see Fig.7, Fig. 8-a, Fig. 9, Fig. 10-b, Fig. 11-a), the whole CARBO-S-10 series (Fig. 10-a) exhibited a significantly different behavior depending upon whether an optical fiber was attached or not to the rebar. For these specimens equipped with DOFS, a continuous increase of the bond stress was observed after the first linear branch of bond-slip curves, whereas a large decrease was recorded after the pic stress for companion non-instrumented specimens. A similar difference in the bond behavior was also observed for the GLASS-NS-12.7 series (Fig 8.b). From the author's point of view, this phenomenon could be attributed to some local surface roughness formed by the adhesive when bonding the optical fiber to the rebar, which increases friction during pull-out of the bar. However, authors cannot explain why such local roughness was formed only in the case of instrumented CARBO-S-10 and GLASS-NS-12.7 rebars. Later, we will use DOFS measurements to study the interface behavior at a more local scale, but the reader should keep in mind that such instrumentation affects significantly the bond behavior for these two types of specimens (CARBO-S-10 and GLASS-NS-12.7). It should be noted that previous studies did not reveal any change in the bond behavior associated with optical fiber instrumentation in the case of deformed steel rebars [13-15].

When focusing on the effect of the bar diameter, and in view of experimental results for specimens with rebars of the GLASS-S subseries (3 different diameters in the range 9.5-15.9 $\mathrm{mm}$ ) and ARA-S subseries ( 2 different diameters, 9 and $15 \mathrm{~mm}$ ), it can be concluded that the 
bond strength globally increases with the bar diameter. It is worth mentioning that the inverse trend is usually reported in the literature $[4,5,10,19,23]$. Note, however, that for pull-out tests performed in the present study, all rebars were embedded over a length corresponding to six times their diameter. A constant ratio between embedded length and diameter (here a ratio of six) for all specimen was chosen to facilitate the comparison of bond characteristics, as it produces also a constant ratio between the applied tensile stress $\left(\sigma_{l}\right)$ in the free part of the rebars at bond failure ( $\sigma_{1}=4 F_{1} / \pi d^{2}$, if $F_{1}$ is the ultimate load) and the bond strength $\left(\tau_{1}=F_{1} / 6 \pi d^{2}\right)$. In these conditions the ratio $\sigma_{1} / \tau_{1}=24$ is independent of the rebar diameter. However, as a direct consequence, the embedment length varies with the bar diameter.

Table 4. Results of pull-out tests

\begin{tabular}{|c|c|c|c|}
\hline & $\begin{array}{l}\text { Ultimate } \\
\text { capacity } F_{1}(\mathrm{kN})\end{array}$ & $\begin{array}{l}\text { Bond strength } \\
\tau_{1}(\mathrm{MPa})\end{array}$ & $\begin{array}{l}\text { Tensile stress" } \\
\sigma_{I}(\mathrm{MPa})\end{array}$ \\
\hline GLASS-S-9.5-1 & 15.6 & 9.2 & 220 \\
\hline GLASS-S-9.5-2 & 13.9 & 8.1 & 195 \\
\hline GLASS-S-9.5-3-OF & 11.8 & 7.0 & 167 \\
\hline GLASS-S-9.5-4-OF & 13.4 & 7.9 & 189 \\
\hline Mean & $13.7 \pm 1.3$ & $8.0 \pm 0.8$ & $193 \pm 19$ \\
\hline GLASS-S-12.7-1 & 32.7 & 10.7 & 258 \\
\hline GLASS-S-12.7-2 & 30.1 & 9.9 & 237 \\
\hline GLASS-S-12.7-3-OF & 28.2 & 9.3 & 223 \\
\hline GLASS-S-12.7-4-OF & 33.8 & 11.1 & 267 \\
\hline Mean & $31.2 \pm 2.2$ & $10.3 \pm 0.7$ & $246 \pm 17$ \\
\hline GLASS-S-15.9-1 & 55.6 & 11.7 & 280 \\
\hline GLASS-S-15.9-2 & 56.6 & 11.9 & 285 \\
\hline GLASS-S-15.9-3-OF & 46.2 & 9.7 & 233 \\
\hline GLASS-S-15.9-4-OF & 52.7 & 11.1 & 265 \\
\hline Mean & $52.8 \pm 4.0$ & $11.1 \pm 0.8$ & $266 \pm 20$ \\
\hline GLASS-NS-12.7-1 & $\overline{5.1}$ & 1.7 & 40 \\
\hline GLASS-NS-12.7-2 & 4.5 & 1.5 & 36 \\
\hline GLASS-NS-12.7-3-OF & 5.8 & 1.9 & 46 \\
\hline GLASS-NS-12.7-4-OF & 5.7 & 1.9 & 45 \\
\hline Mean & $5.3 \pm 0.5$ & $1.7 \pm 0.2$ & $42 \pm 4$ \\
\hline CARBO-S-10-1 & 11.5 & 6.1 & 147 \\
\hline CARBO-S-10-2 & 11.0 & 5.8 & 140 \\
\hline CARBO-S-10-3-OF & 13.4 & 7.1 & 171 \\
\hline CARBO-S-10-4-OF & 14.7 & 7.8 & 187 \\
\hline Mean & $12.7 \pm 1.5$ & $6.7 \pm 0.8$ & $161 \pm 19$ \\
\hline CARBO-NS-10-1 & 9.6 & 5.1 & 122 \\
\hline
\end{tabular}




\begin{tabular}{lrrr}
\hline & \multicolumn{1}{l}{$\begin{array}{l}\text { Ultimate } \\
\text { capacity } \boldsymbol{F}_{\boldsymbol{1}}(\mathbf{k N})\end{array}$} & $\begin{array}{l}\text { Bond strength } \\
\left.\tau_{\boldsymbol{l}} \mathbf{( M P a}\right)\end{array}$ & \multicolumn{2}{c}{ Tensile stress $^{*} \boldsymbol{\sigma}_{\mathbf{l}} \mathbf{( \mathbf { M P a } )}$} \\
\hline CARBO-NS-10-2 & 10.3 & 5.5 & 131 \\
CARBO-NS-10-3-OF & 13.4 & 7.1 & 171 \\
CARBO-NS-10-4-OF & 10.7 & 5.7 & 136 \\
Mean & $\mathbf{1 1 . 0} \pm \mathbf{1 . 5}$ & $\mathbf{5 . 8} \pm \mathbf{0 . 8}$ & $\mathbf{1 4 0} \pm \mathbf{1 9}$ \\
\hline ARA-S-9-1 & 10.6 & 6.9 & 166 \\
ARA-S-9-2 & 9.8 & 6.4 & 153 \\
ARA-S-9-3-OF & 9.7 & 6.4 & 153 \\
ARA-S-9-4-OF & 10.3 & 6.8 & 162 \\
Mean & $\mathbf{1 0 . 1} \pm \mathbf{0 . 4}$ & $\mathbf{6 . 6} \pm \mathbf{0 . 2}$ & $\mathbf{1 5 9} \pm \mathbf{6}$ \\
\hline ARA-S-15-1 & 41.9 & 9.9 & 237 \\
ARA-S-15-2 & 43.3 & 10.2 & 245 \\
ARA-S-15-3-OF & 37.8 & 8.9 & 214 \\
ARA-S-15-4-OF & 32.0 & 7.5 & 181 \\
Mean & $\mathbf{3 8 . 7} \pm \mathbf{4 . 4}$ & $\mathbf{9 . 1} \pm \mathbf{1 . 0}$ & $\mathbf{2 1 9} \pm \mathbf{2 5}$ \\
\hline STEEL-D-12-1 & 25.8 & 9.5 & 228 \\
STEEL-D-12-2 & 25.7 & 9.5 & 227 \\
STEEL-D-12-3-OF & 22.3 & 8.2 & 197 \\
STEEL-D-12-4-OF & 30.6 & 11.3 & 271 \\
Mean & $\mathbf{2 6 . 1} \pm \mathbf{3 . 0}$ & $\mathbf{9 . 6} \pm \mathbf{1 . 1}$ & $\mathbf{2 3 1} \pm \mathbf{2 6}$ \\
\hline
\end{tabular}

* Tensile stress in the loaded part of the rebar at bond failure

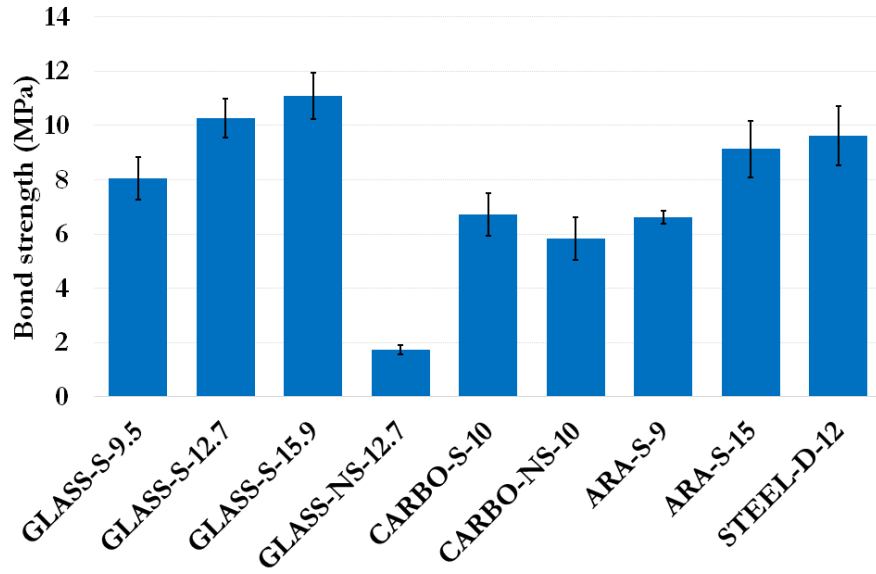

Fig 12. Summary of the bond strengths obtained for the various specimens 


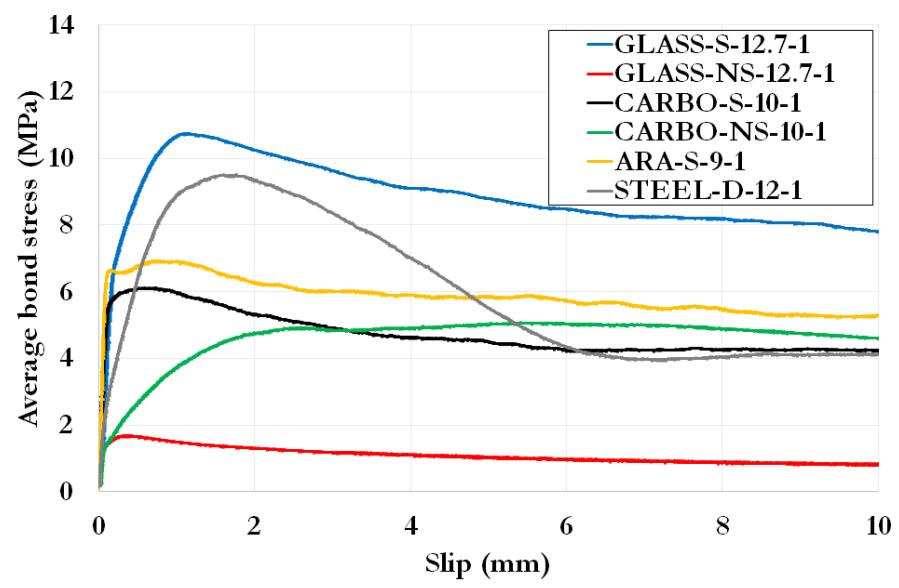

Fig 13. Comparison of typical bond-slip curves for the various types of bars

Previous results show globally a complex interface behavior, depending:

- on the nature of the constituent materials and the surface characteristics of the considered rebar, as already seen in the literature $[\mathbf{2 - 5}, \mathbf{1 0}]$,

- on its diameter, although the results of the present study differ with the trend usually reported in the literature $[4,5,10,19,23]$.

To perform a deeper analysis, it was therefore decided to study the interface mechanisms at a more local level, using strain profiles recorded during pull-out tests on specimens instrumented over their entire embedded length by DOFS.

\subsection{Analysis of the local bond behavior using DOFS instrumentation}

\subsubsection{Strain distribution along the embedded length}

Before moving forward, let's recall that the embedment length correspond to the length along which the rebar is in contact with concrete, while the "development length" is the part of the embedded length over which the rebar actually transfers the applied longitudinal force to the surrounding concrete. As previously stated, the embedded length is equal to six times the diameter of the rebar for all pull-out specimens considered in this study. 
Longitudinal strain distributions measured during pull-out tests by the DOFS attached to the rebars are shown in Fig $\mathbf{1 4}$ to Fig 20, for several load levels corresponding to about 20, 40 and $80 \%$ (exact values are specified in the figures) of the bond strength of each considered type of rebar (see Table 4). However, considering i) that the pull-out response of samples of the CARBO-S-10 and GLASS-NS-12.7 series was altered by the presence of DFOS and ii) that this difference was only noticeable after the first linear branch of bond-slip curves of these series, the analysis of strain profiles performed later in this section was accomplished taking into account experimental measurements recorded at low load level only, corresponding to approximately $20 \%$ of the bond strength.

On the curves displayed in Fig 14 to Fig 20, the two ends of the embedded length are indicated by two vertical black dotted lines. The strain decreases progressively from the loaded end $(x<0)$ to the free end of the rebar. Note that strain profiles could not be recorded during pull-out tests on specimens with ARA-S-9-4-OF, ARA-S-15-3-OF, CARBO-S-10-3OF and STEEL-D-12-4-OF rebars, due to failure of the optical fibers during sample preparation or handling.
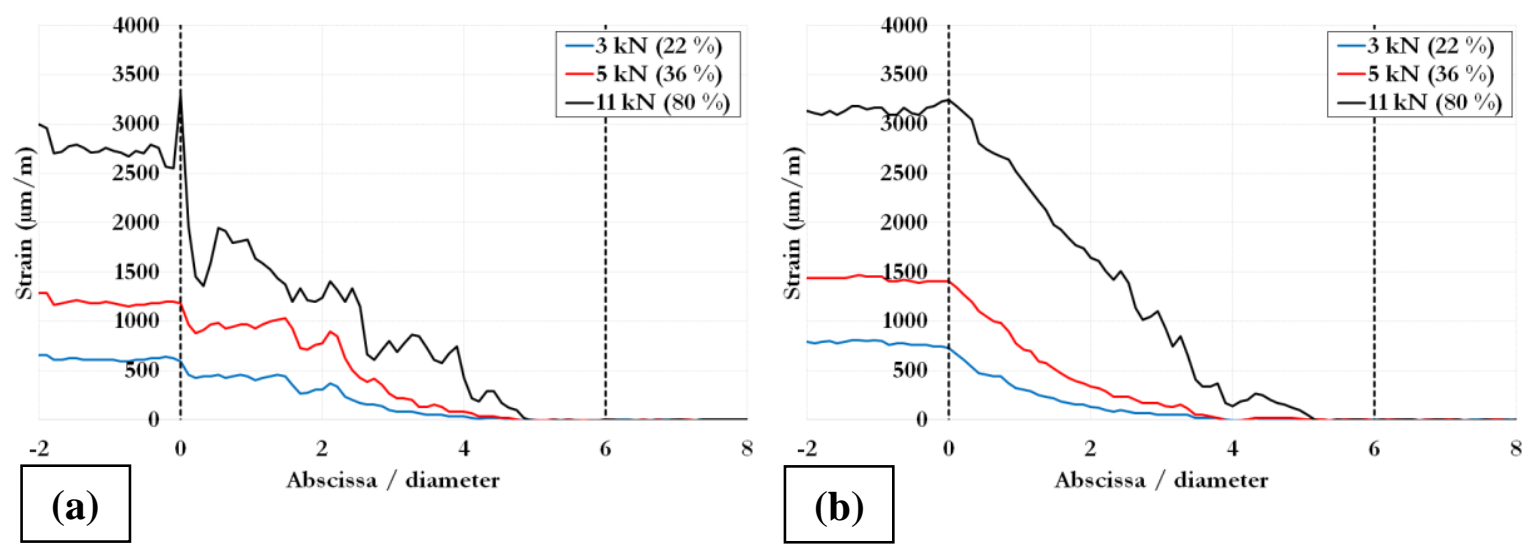

Fig 14. Strain distribution measured during pull-out tests along the embedded length of (a) GLASS-S-9.5-3-OF and (b) GLASS-S-9.5-4-OF rebars 

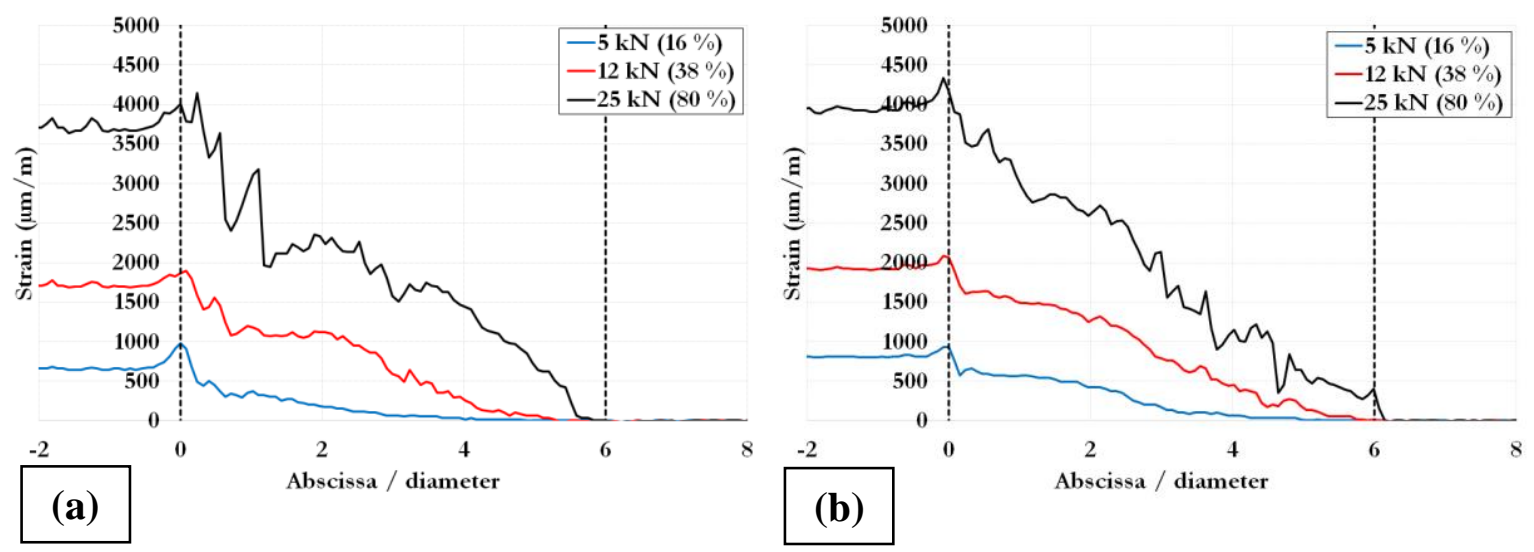

Fig 15. Strain distribution measured during pull-out tests along the embedded length of (a) GLASS-S-12.7-3-OF and (b) GLASS-S-12.7-4-OF rebars
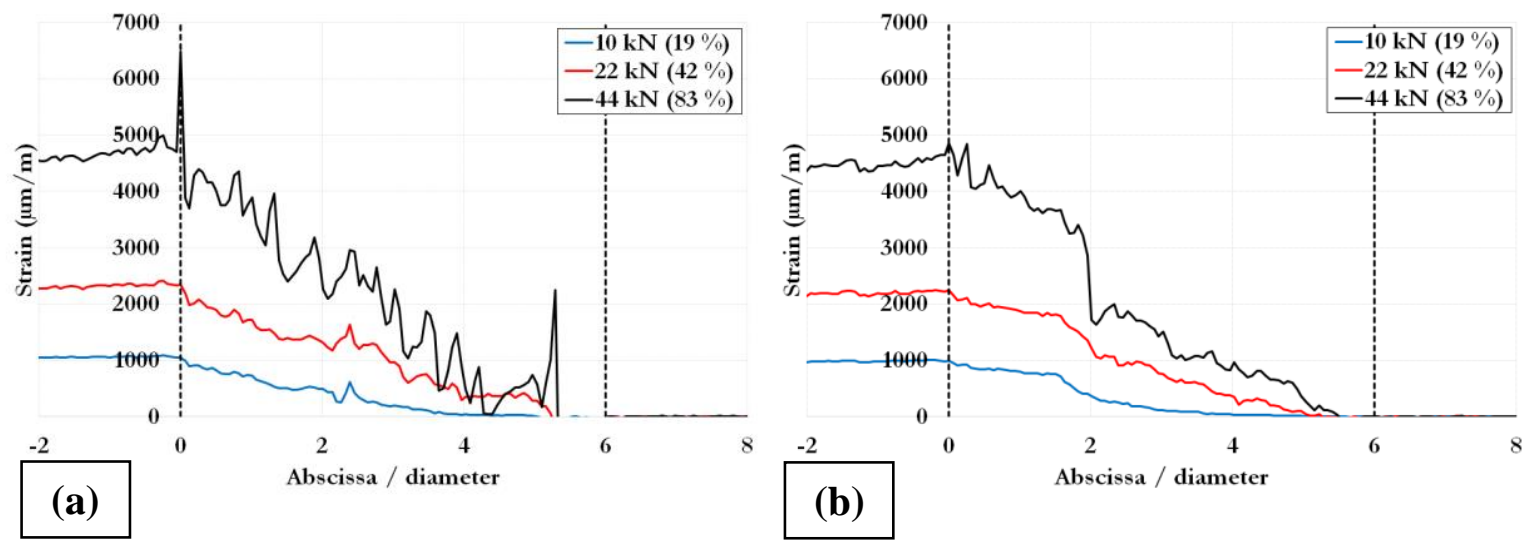

Fig 16. Strain distribution measured during pull-out tests, along the embedded length of

(a) GLASS-S-15.9-3-OF and (b) GLASS-S-15.9-4-OF rebars
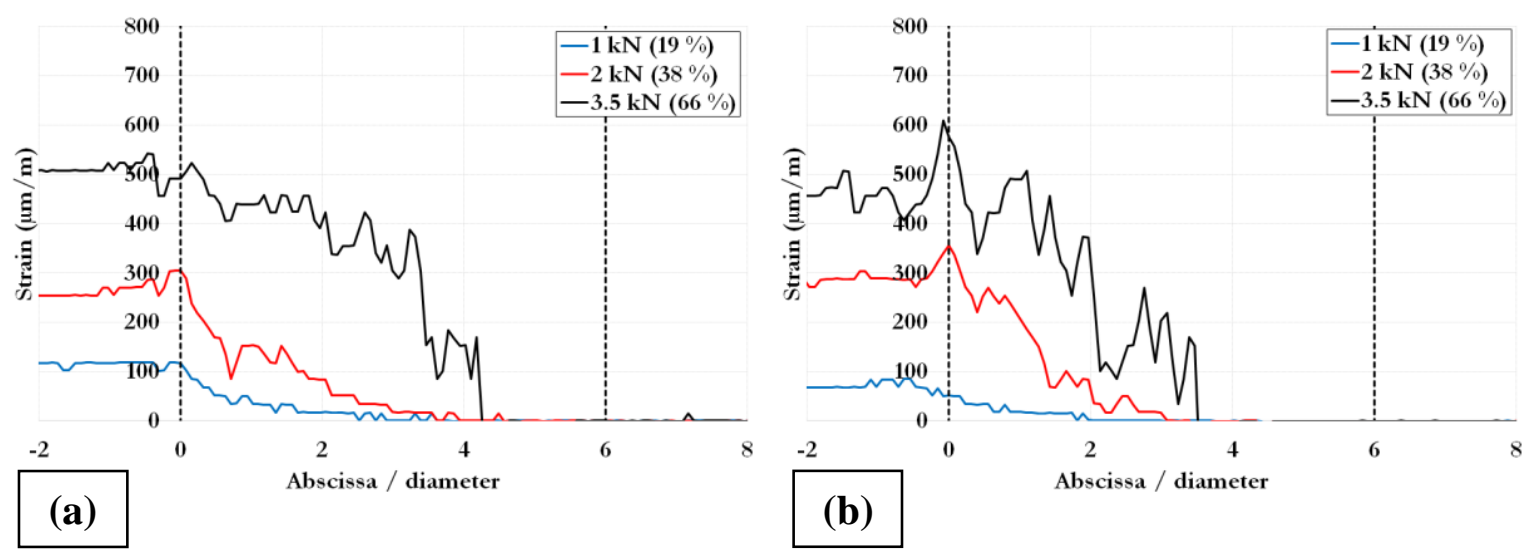

Fig 17. Strain distribution measured during pull-out tests along the embedded length of (a) GLASS-NS-12.7-3-OF and (b) GLASS-NS-12.7-4-OF rebars 

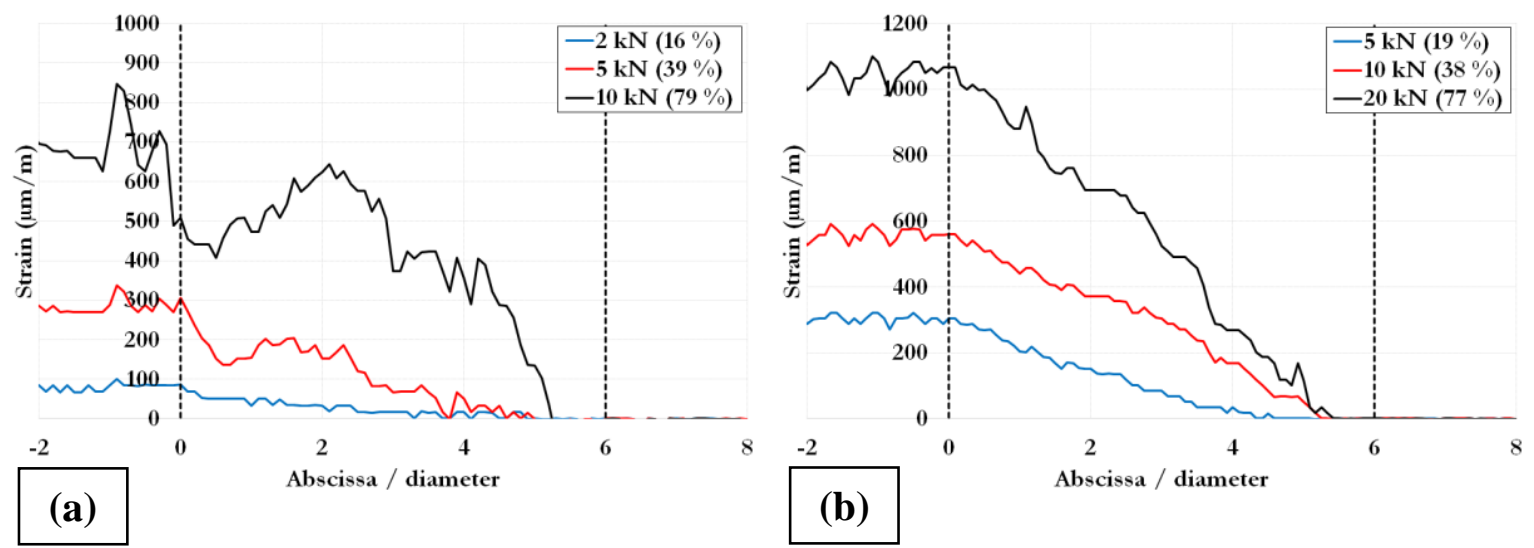

Fig 18. Strain distribution measured during pull-out tests along the embedded length of

(a) CARBO-S-10-4-OF and (b) STEEL-D-12-3-OF rebars
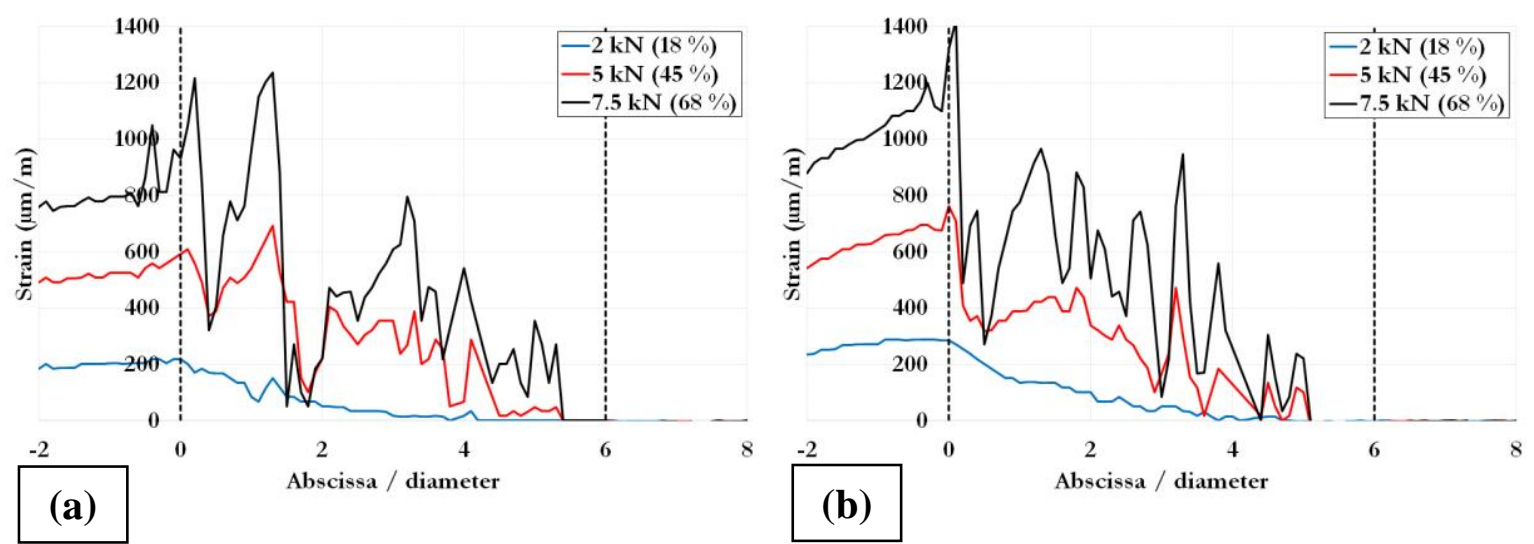

Fig 19. Strain distribution measured during pull-out tests along the embedded length of

(a) CARBO-NS-10-3-OF and (b) CARBO-NS-10-4-OF rebars
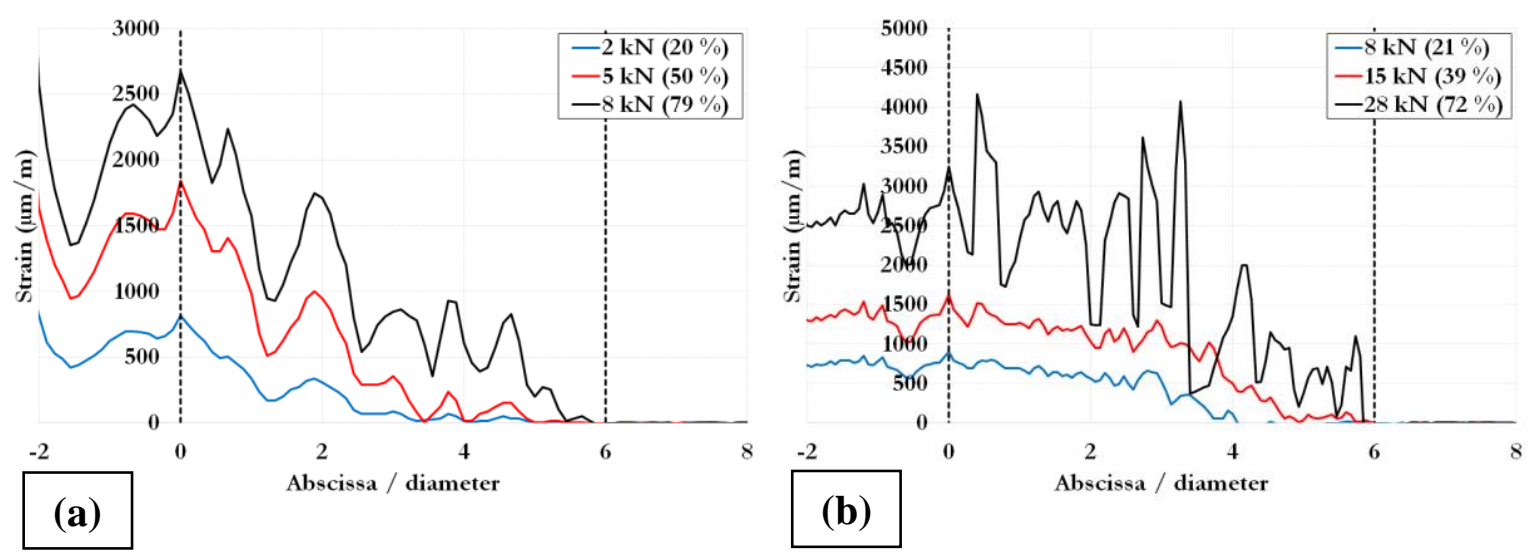

Fig 20. Strain distribution measured during pull-out tests along the embedded length of (a) ARA-S-9-3-OF and (b) ARA-S-15-4-OF rebars

According to the literature $[\mathbf{2 4 , 2 5}$, characteristics of the stress distribution are as follow: the maximum stress value is located near the loaded end of the rebar, then stress decreases 
towards the free end and finally vanishes. It is to note that, assuming a perfect initial positioning of the rebars in the concrete cylinder, pull-out loading leads to a constant tension of the free length of the rebar. However, as ever underlined by other authors [26], any slight deviations from an ideal axial alignment will generate a component of bending and an induced non constant strain profile of the free length of the rebar (see for example Fig. 19.b and Fig 20.a). In the present study, development lengths are found to be lower than embedded lengths for all rebars. At the lowest load level (corresponding roughly to $20 \%$ of the mean bond strength), strains are mainly concentrated at the beginning of the embedded area, near the loaded end. No obvious sign of interfacial damage can be detected at such low load level. As load increases, the concrete/rebar interface becomes increasingly damaged and strains are progressively redistributed over the entire embedded length.

It is interesting to note that a waving effect is observed on most experimental strain distribution curves. This can be explained by the fact that the DOFS is installed close to the concrete/rebar interface, and measured strain is thus locally affected by the surface geometry of the rebar [15]. In Fig 20, the strain profiles obtained for specimens with ARA-S rebars present wave forms showing a period in the order of one $\mathrm{cm}$, in line with the surface geometry of braided aramid ropes (presence of concavo-convex shapes with a spatial period of one $\mathrm{cm}$, due to the braiding process). Similarly, waves forms observed on strain profiles of specimens with CARBO rebars (see Fig 18 and Fig 19), may also originate from the periodic surface relief associated to the white yarn helically wrapped around the bars (Cf. Fig 1).

\subsubsection{Assessment of the development length}

Strain profiles were recorded during pull-out tests, which made it possible to assess the development lengths of the various rebars under consideration. In order to use an objective and reproducible quantification method, the definition of the development length proposed by 
Yuan [27] was adopted. This author defined the development length as the length $L_{D}$ necessary to transfer $97 \%$ of the force applied to the rebar. It has recently been applied to the processing of experimental data in the field of adhesive bonding [28, 29]. Following this approach, the criterion for determining the development length is written as follows:

$$
\int_{0}^{L_{D}} \pi d \tau(x) d x=0.97 F
$$

with :

$$
F=\int_{0}^{L_{E}} \pi d \tau(x) d x
$$

where $L_{D}$ the development length, $d$ the rebar diameter, $\tau(x)$ the bond stress at the abscissa $x$ (along the rebar), $d x$ an infinitesimal length of the rebar, $F$ the tensile force applied to the rebar and $L_{E}$ the embedment length in concrete.

Considering the force equilibrium of an elemental portion the rebar of length $d x$ anchored in the concrete (Fig 21), the equilibrium can be written as below [13]:

$$
\pi d \tau(x) d x=\pi\left(\frac{d}{2}\right)^{2}\left[\sigma_{x x}(x)-\sigma_{x x}(x+d x)\right]
$$

where $\sigma_{x x}(x)$ is the tensile stress in the rebar at the abscissa $x$.

Assuming a linear elastic behavior of the FRP rebar and using Hooke's law, the tensile stress can be expressed as:

And considering:

$$
\sigma_{x x}(x)=E \varepsilon_{x x}(x)
$$

$$
\left[\sigma_{x x}(x)-\sigma_{x x}(x+d x)\right]=-\frac{d \sigma_{x x}}{d x}(x) d x
$$

Then, Eq. 4 becomes:

$$
\tau(x)=-\left(\frac{d}{4}\right) \frac{d \sigma_{x x}}{d x}(x)=-\left(\frac{d}{4}\right) E \frac{d \varepsilon_{x x}}{d x}(x)
$$

The previous criterion (Eq. 2 and 3) can therefore be written as follows: 


$$
\begin{aligned}
\pi \frac{d^{2}}{4} E \int_{0}^{L_{D}}-\frac{d \varepsilon_{x x}}{d x}(x) d x & =0.97 \pi \frac{d^{2}}{4} E \int_{0}^{L_{E}}-\frac{d \varepsilon_{x x}}{d x}(x) d x \\
\varepsilon_{x x}(0)-\varepsilon_{x x}\left(L_{D}\right) & =0.97\left[\varepsilon_{x x}(0)-\varepsilon_{x x}\left(L_{E}\right)\right]
\end{aligned}
$$

And finally comes:

$$
\varepsilon_{x x}\left(L_{D}\right)=0.03 \varepsilon_{x x}(0)
$$

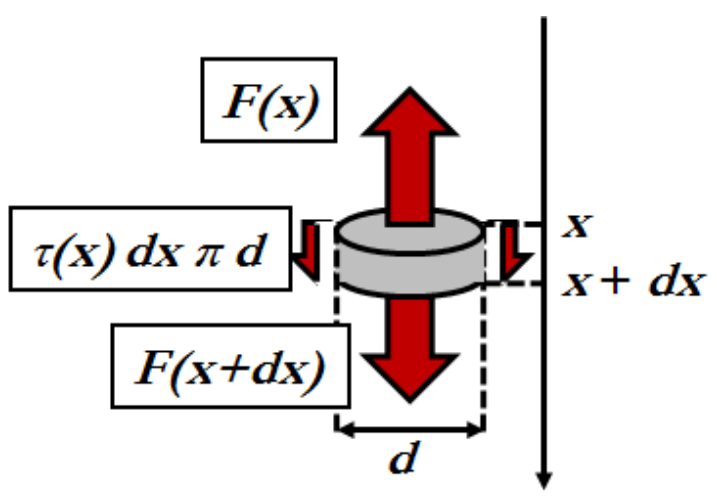

Fig 21. Equilibrium of forces on a section of rebar anchored in concrete

Based on the proposed approach, values of the development lengths were estimated for each type of rebar, considering experimental strain measurements recorded at the lowest load level (around of $20 \%$ of the bond strength), and assuming that the interface remained undamaged. Calculated values of the development length are listed in Table $\mathbf{5}$ and are also summarized in the form of a bar graph in Fig 22.

Results point out an increase in the development length as a function of the bar diameter, for a given series of rebars (Fig 22). This trend is consistent with the literature [25, 30, 31].

With regard to the effect of sand coating, the uncoated rebars GLASS-NS-12.7-OF present a much lower development length than the sand coated rebars GLASS-S-12.7-OF. The opposite trend is observed for rebars of the CARBO series (slightly lower development length obtained for the sand-coated rebars), but this latter result should be taken with circumspection, as the 
DOFS instrumentation was previously reported to affect significantly the pull-out response of CARBO-S-10-OF specimens (cf. section 3.2.2).

Moreover, no clear trend can be established regarding the effect of the elastic modulus of the rebars (and hence the nature of the fibers) on the development length, as shown in Fig 23. Globally, all these results attest to the complexity of interfacial mechanisms between the FRP reinforcements and surrounding concrete.

Table 5. Development lengths calculated for the various rebars

\begin{tabular}{|c|c|c|}
\hline & $\begin{array}{l}\text { Development } \\
\text { length } L_{D}(\mathrm{~mm})\end{array}$ & $L_{D} / d$ \\
\hline GLASS-S-9.5-3-OF & 40 & 4.2 \\
\hline GLASS-S-9.5-4-OF & 33 & 3.5 \\
\hline Mean & $36.5 \pm 3.5$ & $3.8 \pm 0.4$ \\
\hline GLASS-S-12.7-3-OF & 51 & 4.0 \\
\hline GLASS-S-12.7-4-OF & 63 & 5.0 \\
\hline Mean & $57 \pm 6$ & $4.5 \pm 0.5$ \\
\hline GLASS-S-15.9-3-OF & 70 & 4.4 \\
\hline GLASS-S-15.9-4-OF & 73 & 4.6 \\
\hline Mean & $71.5 \pm 1.5$ & $4.5 \pm 0.1$ \\
\hline GLASS-NS-12.7-3-OF & 32 & 2.5 \\
\hline GLASS-NS-12.7-4-OF & 23 & 1.8 \\
\hline Mean & $27.5 \pm 4.5$ & $2.2 \pm 0.4$ \\
\hline CARBO-S-10-3-OF & Not available & - \\
\hline CARBO-S-10-4-OF & 33 & 3.3 \\
\hline Mean & 33 & 3.3 \\
\hline CARBO-NS-10-3-OF & 38 & 3.8 \\
\hline CARBO-NS-10-4-OF & 38 & 3.8 \\
\hline Mean & $38 \pm 0$ & $3.8 \pm 0.0$ \\
\hline ARA-S-9-3-OF & 30 & 3.3 \\
\hline ARA-S-9-4-OF & Not available & - \\
\hline Mean & 30 & 3.3 \\
\hline ARA-S-15-3-OF & Not available & - \\
\hline ARA-S-15-4-OF & 61 & 4.1 \\
\hline Mean & 61 & 4.1 \\
\hline STEEL-D-12-3-OF & 52 & 4.3 \\
\hline STEEL-D-12-4-OF & Not available & - \\
\hline Mean & 52 & 4.3 \\
\hline
\end{tabular}




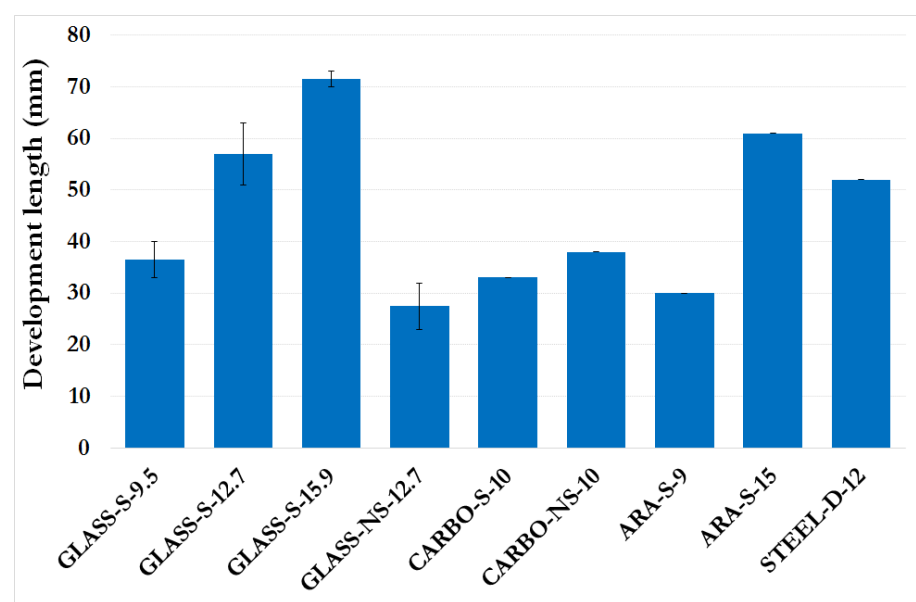

Fig 22. Development lengths of the various rebars (averaged values based on two tests)

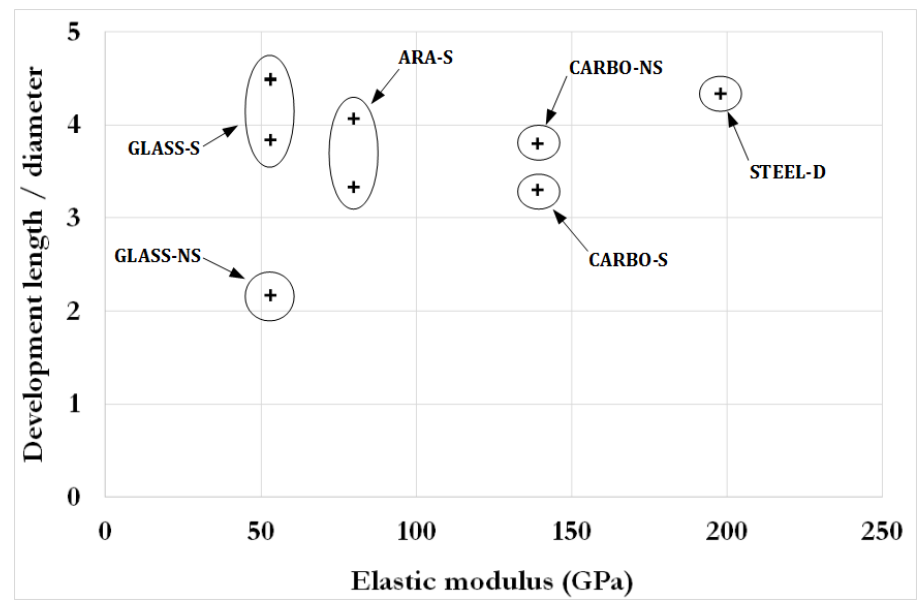

Fig 23. Development length versus elastic modulus for the various rebars under study. Elastic moduli were previously determined by tensile tests (see Table 3)

\section{Conclusions}

The various FRP composite rebars were first characterized by tensile test while their surfaces were observed by SEM. These preliminary characterizations showed that tensile properties are in line (or even better) with values reported by the manufacturers, and revealed substantial differences in the size and shape of particles from the sand coatings.

The bond-slip behavior of the various rebars embedded in concrete cylinders was then determined by pull-out tests. An original aspect of this experimental work lies in the 
instrumentation of specimens by distributed optical fiber sensors attached to the rebar surface. This DOFS device provided access to local information related to interfacial load transfer mechanisms, such as the longitudinal strain profile along the embedded length or the effective development length of the rebars. This latter is an essential criterion in the design of the anchorage. Nevertheless, this instrumentation was found to be intrusive for few rebars (CARBO-S and GLASS-NS), and strain measurement should be interpreted with caution in these specific cases.

Following this experimental campaign, it has been globally noted that characteristics of the sand coating play a major role in the load transfer mechanism at the interface (rigidity of the interface, bond strength and post-peak stress plateau related to friction). Efficiency of the sand coating tends to increase with the size and angulosity of the sand particles. The sand coating of GLASS-S was found to provide higher bond performances compared to that of CARBO-S series or ARA-S series, although these latter rebars exhibit additional surface relief due to the braiding process.

For equivalent bar diameters, pull-out specimens with GLASS-S-12.7 rebars exhibited slightly higher bond strength values compared to specimens with reference deformed steel rebars (STEEL-D-12), which is quite encouraging.

In addition, experimental results showed an increase in bond strength versus the bar diameter, although an inverse trend is usually reported in the literature.

Interpretation of strain profiles recorded by DOFS instrumentation made it possible to estimate the development length of each bar. Results revealed an increase in the development length with the bar diameter, but no clear effect of the elastic modulus of rebars (which is closely related to the nature/stiffness of fibers).

More generally, the diversity of strain profiles highlighted the complex distribution of shear stresses and the multiple phenomena involved in the load transfer mechanisms between 
concrete and its FRP reinforcement. Such a complexity may originate from the high variability in the FRP characteristics, depending on many factors, such as the nature and relative contents of constituent materials (fibers and polymer matrix), the type of surface coating and geometry, or the manufacturing process.

Additional studies are needed to investigate further the bond behavior of FRP rebars with concrete at the local level. This knowledge is essential for establishment of suitable design standards and for further optimization of FRP rebar characteristics (surface coating, manufacturing process...).

\section{Acknowledgments}

The authors wish to acknowledge Pultrall ${ }^{\circledR}$, Sireg ${ }^{\circledR}$ and Fibex ${ }^{\circledR}$ companies for supplying FRP rebars used in this study.

\section{References}

[1] EN 1992-1-1 Eurocode 2 - Design of concrete structures - Part 1-1: General rules and rules for buildings, Comité Européen de Normalisation (CEN), Brussels, Belgium, 2004.

[2] J. Larralde, R. Silva-Rodriguez, Bond and slip of FRP rebars in concrete, Journal of Materials in Civil Engineering 5 (1) (1993) 30-40.

[3] E. Cosenza, G. Manfredi, R. Realfonzo, Behavior and modeling of bond of FRP rebars to concrete, Journal of Composites for Construction 1 (2) (1997) 40-51.

[4] B. Tighiouart, B. Benmokrane, D. Gao, Investigation of bond in concrete member with fibre reinforced polymer (FRP) bars, Construction and Building Materials 12 (8) (1998) 453462.

[5] R. Okelo, R.L. Yuan, Bond strength of fiber reinforced polymer rebars in normal strength concrete, Journal of Composites for Construction 9 (3) (2005) 203-213. 
[6] ACI 440.3R-04, Guide test methods for fiber-reinforced polymers (FRPs) for reinforcing or strengthening concrete structures, American Concrete Institute (ACI), Farmington Hills, MI, USA, 2004.

[7] RILEM (1983). "RC 6 Bond test for reinforcement steel. 2. Pull-out test". RILEM Recommendations for the Testing and Use of Constructions Materials. pp. 218-220.

[8] EN 10080 Steel for the reinforcement of concrete - Weldable reinforcing steel - General, Comité Européen de Normalisation (CEN), Brussels, Belgium, 2005.

[9] L.C. Bank, M. Puterman, A. Katz, The effect of material degradation on bond properties of fiber reinforced plastic reinforcing bars in concrete, ACI Materials Journal 95 (3) (1998) 232-243.

[10] Z. Achillides, P. Pilakoutas, Bond behavior of fiber reinforced polymer bars under direct pull-out conditions, J. Compos. Constr. 8 (2) (2004) 173-181.

[11] M. Robert, B. Benmokrane, Effect of aging on bond of GFRP bars embedded in concrete, Cement \& Concrete Composites 32 (1) (2010) 461-467.

[12] J.-M. Henault, M. Quiertant, S. Delepine-Lesoille, J. Salin, G. Moreau, F. Taillade, K. Benzarti, Quantitative strain measurement and crack detection in RC structures using a truly distributed fiber optic sensing system, Construction and Building Materials 37 (1) (2012) 916923.

[13] M. Quiertant, F. Baby, A. Khadour, P. Marchand, P. Rivillon, J. Billo, R. Lapeyrere, F. Toutlemonde, A. Simon, J. Cordier, J.-C. Renaud, Deformation monitoring of reinforcement bars with a distributed fiber optic sensor for the SHM of reinforced concrete structures, $9^{\text {Th }}$ International Conference on NDE in Relation to Structural Integrity for Nuclear and Pressurized Components, Seattle, Washington, USA, 2012.

[14] A. Khadour, F. Baby, A. Herrera, F. Taillade, P. Marchand, P. Rivillon, A. Simon, M. Quiertant, F. Toutlemonde, Distributed strain monitoring of reinforcement bars using optical 
fibers for SHM, $7^{\text {th }}$ International Conference on Concrete under Severe Conditions (CONSEC13) - Environment and Loading, Nanjing, China, 2013, pp. 1620-1629.

[15] P. Marchand, F. Baby, A. Khadour, T. Battesti, P. Rivillon, M. Quiertant, H.-H. Nguyen, G. Généreux, J.-P. Deveaud, A. Simon, F. Toutlemonde, Bond behaviour of reinforcing bars in UHPFRC, Materials and Structures 49 (5) (2016) 1979-1995.

[16] ASTM D7205/D7205M-06, Standard test method for tensile properties of fiber reinforced polymer matrix composite bars, American Society for Testing and Materials (ASTM), West Conshohocken, PA, USA, 2006.

[17] A. Rolland, Comportement mécanique et durabilité de structures en béton renforcées par des armatures composites internes, PhD thesis manuscript, Université Paris-Est, France, 2015, 235 pages (in French). https://tel.archives-ouvertes.fr/tel-01223307/document

[18] A. Rolland, S. Chataigner, K. Benzarti, M. Quiertant, P. Argoul, J.-M. Paul, Experimental investigation and modelling of the bond between aramid fiber-reinforced polymer bars and concrete, in: Materials and Infrastructures 1, Willey-ISTE, John Wiley and Sons, Inc., Hoboken, New Jersey, 2016, pp. 115-128.

[19] L.C. Bank, Composites for construction: structural design with FRP materials, John Wiley and Sons, Inc., Hoboken, New Jersey, 2006.

[20] L.C. Hollaway, Advanced fibre polymer composite structural systems used in bridge engineering, ICE Manual of Bridge Engineering, 2008, pp. 503-529.

[21] M. Froggatt, J. Moore, High-spatial-resolution distributed strain measurement in optical fiber with Rayleigh scatter, Appl. Opt. 37 (1998) 1735-1740.

[22] B. Soller, D. Gifford, M. Wolfe, M. Froggatt, High resolution optical frequency domain reflectometry for characterization of components and assemblies, Opt Express 13 (2005) 666674. 
[23] F. Sayed Ahmad, Mise en précontrainte des bétons fibrés à ultra performance (BFUP) à l'aide de polymères renforcés de fibres de carbone (PRFC), $\mathrm{PhD}$ thesis manuscript, Université Paris-Est, France, 2011, 250 pages (in French). https://tel.archives-ouvertes.fr/pastel00700491/document

[24] F. Focacci, A. Nanni, C.E. Bakis, Local bond-slip relationship for FRP reinforcement in concrete, Journal of Composites for Construction 4 (1) (2000) 24-31.

[25] N. Newman, A. Ayoub, A. Belarbi, Development length of straight FRP composite bars embedded in concrete, Journal of Reinforced Plastics and Composites 29 (4) (2010) 571-589.

[26] B. Forbes, N. Vlachopoulos, M. S. Diederichs, Improving Ground Support Design with Distributed Strain Monitoring, 68th Canadian Geotechnical Conference and 7th Canadian Permafrost Conference, At GEOQuébec, Québec City, Canada, 2015.

[27] H. Yuan, Improved theoretical solutions of FRP-to-concrete interfaces, Proceedings. of the International Symposium on Bond Behaviour of FRP in Structures (BBFS), Hong Kong, China, 2005, pp. 97-102.

[28] A. Billon, J.-M. Henault, M. Quiertant, F. Taillade, A. Khadour, R.-P. Martin, K. Benzarti, Qualification of a distributed optical fiber sensor bonded to the surface of a concrete structure: A methodology to obtain quantitative strain measurements, Smart Materials and Structures 2015, Vol. 24 (11), 115001.

[29] N. Houhou, K. Benzarti, M. Quiertant, S. Chataigner, A. Flety and C. Marty, Analysis of the nonlinear creep behavior of concrete/FRP-bonded assemblies, Journal of Adhesion Science and Technology 2014, Vol. 28 (14-15), 1345-1366

[30] CSA S806-12, Design and construction of building structures with fibre-reinforced polymers, Canadian Standards Association (CSA), Mississauga, ON, Canada, 2012. 
[31] ACI 440.1R-15, Guide for the design and construction of structural concrete reinforced with fiber-reinforced polymer bars, American Concrete Institute (ACI), Farmington Hills, MI, USA, 2015. 